\title{
Interpolymer complexes of Carbopo/ß 971 and poly(2-ethyl-2-oxazoline): physicochemical studies of complexation and formulations for oral drug delivery
}

Article

Accepted Version

Creative Commons: Attribution-Noncommercial-No Derivative Works 4.0

Moustafine, R. I., Victorova, A. S. and Khutoryanskiy, V. V. (2019) Interpolymer complexes of Carbopol® 971 and poly(2ethyl-2-oxazoline): physicochemical studies of complexation and formulations for oral drug delivery. International Journal of Pharmaceutics, 558. pp. 53-62. ISSN 0378-5173 doi: https://doi.org/10.1016/j.ijpharm.2019.01.002 Available at https://centaur.reading.ac.uk/81609/

It is advisable to refer to the publisher's version if you intend to cite from the work. See Guidance on citing.

To link to this article DOI: http://dx.doi.org/10.1016/j.ijpharm.2019.01.002

Publisher: Elsevier

All outputs in CentAUR are protected by Intellectual Property Rights law, including copyright law. Copyright and IPR is retained by the creators or other copyright holders. Terms and conditions for use of this material are defined in the End User Agreement. 


\section{www.reading.ac.uk/centaur}

\section{CentAUR}

Central Archive at the University of Reading

Reading's research outputs online 
Interpolymer complexes of Carbopol ${ }^{\circledR} 971$ and poly(2-ethyl-2-oxazoline): physicochemical studies of complexation and formulations for oral drug delivery

${ }^{1}$ Institute of Pharmacy, Kazan State Medical University, 16 Fatykh Amirkhan Street, 420126

Kazan, Russian Federation

${ }^{2}$ Reading School of Pharmacy, University of Reading, Whiteknights, PO box 224, Reading RG66AD, United Kingdom

\section{Abstract}

Carbopol $^{\circledR} 971$ and poly(2-ethyl-2-oxazoline) form hydrogen-bonded interpolymer complexes in aqueous solutions and their complexation is strongly dependent on solution $\mathrm{pH}$. This work investigated the complexation between these polymers in aqueous solutions. The compositions of interpolymer complexes as well as the critical $\mathrm{pH}$ values of complexation were determined. The structure of these complexes was studied in solutions using transmission electron microscopy and in solid state using elemental analysis, FTIR spectroscopy and differential scanning calorimetry. Solid compacts were prepared based on interpolymer complexes and physical blends of these polymers and their swelling behaviour was studied in aqueous solutions mimicking the fluids present in the gastrointestinal tract. These materials were used to prepare oral formulations of mesalazine and its release from solid matrices was studied in vitro. It was demonstrated that the complexation between $\mathrm{Carbopol}^{\circledR} 971$ and poly(2-ethyl-2oxazoline) has a profound effect on the drug release from matrix tablets.

Keywords: interpolymer complexes, Carbopol $^{\circledR}$, polyoxazoline, hydrogen bonding, nanoparticles, critical $\mathrm{pH}$, mesalazine, oral drug delivery

*Correspondence: Dr Rouslan I. Moustafine rouslan.moustafine@gmail.com and Prof Vitaliy V. Khutoryanskiy v.khutoryanskiy@ reading.ac.uk 


\section{Introduction}

Hydrophilic polymers and their combinations are often used to formulate dosage forms as they provide a number of unique features required for successful drug delivery. When polymer combinations are used for this purpose the performance of the resulting material is often affected by specific attractive interactions occurring between them. The most common types of specific interactions are electrostatic attraction and hydrogen bonding. Electrostatic attraction may occur in combinations of oppositely charged polyelectrolytes and typically results in formation of interpolyelectrolyte complexes (Mustafin, 2011). Hydrogen-bonded interpolymer complexes (IPC) are commonly formed as a result of interactions between polycarboxylic acids, acting as proton donors, and non-ionic water-soluble polymers, exhibiting proton-accepting properties (Bekturov and Bimendina, 1981; Kemenova et al, 1991; Khutoryanskiy, 2007; Kharlampieva et al, 2009).

Poly(2-oxazolines) is an interesting class of functional materials, which is represented by several polymers soluble in water (e.g. poly(2-methyl-2-oxazoline), poly(2-ethyl-2-oxazoline), poly(n-propyl-2-oxazoline, etc). The synthesis of these polymers was first described in the 1960s; however, they received recognition as highly promising biomedical materials only in the last decade (Hoogenboom, 2009; Viegas et al, 2011; Luxenhofer et al, 2012; de la Rosa, 2014; Hoogenboom and Schlaad, 2017; Lorson et al, 2018). Numerous recent studies reported the use of poly(2-oxazolines) in the design of micellar structures for drug delivery (Hruby et al, 2010), vectors for gene therapy (Lehner et al, 2017), hydrogels (Farrugia et al, 2013), polymer-drug/protein conjugates (Mero et al, 2008), and mucus-penetrating nanoparticles (Mansfield et al, 2015; Mansfield et al, 2016). Polyoxazolines are generally non-toxic, biocompatible, and bioinert, which makes them highly promising for various biomedical applications. These polymers are often viewed as an alternative to polyethylene glycols (Bludau et al 2017; Khutoryanskiy, 2018).

Water-soluble poly(2-oxazolines) exhibit a number of interesting physicochemical properties such as temperature-responsive behaviour (Christova et al, 2003; Diehl and Schlaad, 2009; Ambreen and Siddiq, 2014) and proton-accepting ability that facilitates their interactions with proton-donating polymers (Kim et al, 2002). These properties have been successfully utilised in the development of self-assembled materials such as micelles (Filippov et al, 2017), interpolymer complexes and polymeric blends (Dai et al, 1994; Isasi et al, 1996; Kim et al, 2002), and multi-layered constructs (Su et al, 2017; Su et al, 2018). 
The application of poly(2-oxazolines) in the design of solid dosage forms for drug delivery has also received recent interest, but it is still studied insufficiently (Claeys et al, 2012; Policianova et al, 2014; Fael et al, 2018). Recently, interpolymer complexes and physical blends of poly(2-

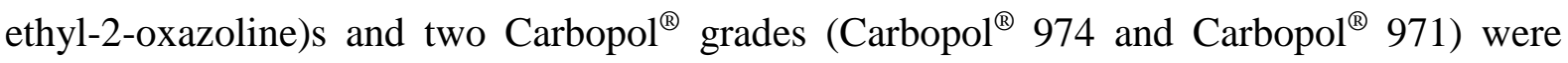
reported for the development of mucoadhesive tablets for buccal delivery of hydrocortisone (Ruiz-Rubio et al, 2018). It was demonstrated that the interaction between these polymers is $\mathrm{pH}$-dependent and the behaviour of tablets is strongly affected by the interactions between the polymers. Taking the $\mathrm{pH}$-responsive nature of these complexes they could also be of interest as materials for oral drug delivery, where a dosage form will experience different $\mathrm{pH}$ environments during its transit through gastrointestinal tract.

In the present study the complexation between Carbopol ${ }^{\circledR} 971$ and poly(2-ethyl-2-oxazoline) of different molecular weights was explored both in solutions and in solid state. The effect of solution $\mathrm{pH}$ on the complexation between polymers was explored and the critical $\mathrm{pHs}$ of complexation were determined. The structure of interpolymer complexes in solid state was studied by elemental analysis, FTIR spectroscopy and differential scanning calorimetry. Solid compacts composed of either IPCs or physical mixtures (PMs) were studied in the media mimicking different parts of gastrointestinal tract. These solid materials were used to formulate a model drug mesalazine relevant for gastrointestinal drug delivery and its release from the dosage forms was studied in vitro.

\section{Materials and Methods}

\subsection{Materials}

Poly(2-ethyl-oxazoline)s (5000, 50000, $500000 \mathrm{~g} \mathrm{~mol}^{-1}$; named as POZ $5 \mathrm{kDa}$, POZ $50 \mathrm{kDa}$ and POZ $500 \mathrm{kDa}$ in the text, respectively) were purchased from Sigma-Aldrich (Irvine, UK)

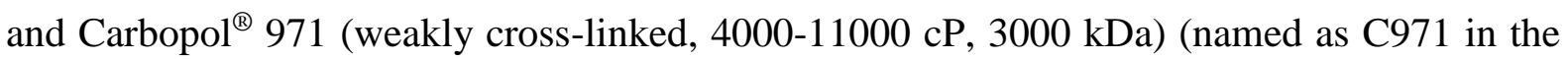
text), was generously donated by Lubrizol Advanced Materials (Wickliffe, OH, U.S.A.). Potassium dihydrogen phosphate, hydrochloric acid and sodium hydroxide were provided by Sigma-Aldrich (Irvine, UK) and used for preparing the media mimicking conditions of gastrointestinal tract. Mesalazine (5-aminosalicylic acid, 5-ASA) was purchased from Sigma-Aldrich (Irvine, UK). A Milli-Q water purification system from Millipore (Bedford, MA, U.S.A.) was used for preparation of all solutions. 


\subsection{Methods}

\subsubsection{IPC formation}

Aqueous mixtures were prepared by mixing 0.002 unit-mol/L individual polymer solutions in deionized water. Solutions were mixed to give different unit molar ratios of the polymer components. The obtained interpolymer complexes (IPCs) were left for 1 hour in the media, and then turbidity of all solutions was measured spectrophotometrically (Lambda 25, Perkin Elmer, Norwalk, CT, U.S.A.) at $400 \mathrm{~nm}$. The complexation between C971 and POZ was initially evaluated in water without adjusting the $\mathrm{pH}$.

For $\mathrm{pH}_{\text {crit }}$ determination, samples were typically analyzed in solutions, whose $\mathrm{pH}$ ranged from 3.0 to 8.0, which was adjusted by adding small portions of $0.1 \mathrm{M} \mathrm{NaOH}$ or $0.1 \mathrm{M}$ $\mathrm{HCl}$. The $\mathrm{pH}$ measurements were performed using a portable $\mathrm{pH}$ meter Orion Star A 325 (Thermo Scientific, U.S.A.) with Orion ${ }^{\mathrm{TM}}$ ROSS Ultra ${ }^{\mathrm{TM}}$ low maintenance $\mathrm{pH} / \mathrm{ATC}$ Triode $^{\mathrm{TM}}$ (Thermo Scientific, U.S.A.). The turbidity of these solutions was measured at $400 \mathrm{~nm}$ using a UV/Vis-spectrophotometer (Lambda 25, Perkin Elmer, Norwalk, CT, U.S.A.). Turbidity readings were taken immediately after adjusting $\mathrm{pH}$. All experiments were repeated in triplicate, and the turbidity values are reported as mean \pm standard deviation.

The composition with the maximal turbidity was selected for the tablet formulation. IPCs were prepared by mixing $0.1 \mathrm{M} \mathrm{POZ}$ and $0.125 \mathrm{M} \mathrm{C} 971$ solutions in acetate buffer $(\mathrm{pH}=3.5)$ and at constant temperature. After isolation of the precipitates from the solutions, they were washed twice with demineralized water and the IPCs were subsequently freeze-dried for 2 days at -27 ${ }^{\circ} \mathrm{C}$ (Labconco ${ }^{\circledR}$ Freeze Dry System, FreeZone 1 L, MO, U.S.A.). The dried IPCs were ground with A 11 basic grinder (IKA ${ }^{\circledR}$ Werke GmbH, Staufen, Germany) and used for further study. The samples were stored in tightly sealed containers at room temperature.

\subsubsection{Transmission electron microscopy (TEM)}

TEM images of IPC were acquired using a JEM 2100 plus TEM (Jeol Ltd., Watchmead England) at $200 \mathrm{kV}$. For sample preparation, the copper grids were brought in contact with dispersions of IPC for $30 \mathrm{~s}$ and then dried off with a filter paper. The $\mathrm{pH}$ of polymer mixtures in aqueous solutions prior to TEM examination was adjusted by adding small amounts of 0.2 $\mathrm{mol} / \mathrm{L} \mathrm{HCl}$ or $\mathrm{NaOH}$ and was measured using a digital $\mathrm{pH}$-meter (Metrohm, Herisau, Switzerland). 


\subsubsection{Elemental analysis}

The composition of freeze-dried IPC (C971/POZ $50 \mathrm{kDa}$ and C971/POZ $500 \mathrm{kDa}$ ) samples and physical mixture (PM) samples before, during, and after swelling testing were investigated by elemental analysis using a Thermo Flash 2000 CHNS/O elemental analyzer (Thermo Fisher Scientific, Paisley, UK). PMs were prepared by mixing C971 and POZ powders at 1.25:1 molar ratio.

\subsubsection{Fourier transform infrared spectroscopy (ATR-FTIR)}

ATR-FTIR-spectra were recorded using a Nicolet iS5 FTIR spectrometer (Thermo Scientific, Waltham, MA, U.S.A.). The untreated freeze-dried samples of solid IPC (C971/POZ $50 \mathrm{kDa}$ and C971/POZ $500 \mathrm{kDa}$ ) and PM samples before, during, and after swelling testing were directly mounted over the iD5 smart single bounce ZnSe ATR crystal. The spectra were analyzed using OMNIC spectra software.

\subsubsection{Thermal analysis}

Modulated DSC (mDSC) measurements were carried out using a Discovery DSC ${ }^{\text {TM }}$ (TA Instruments, New Castle, DE, U.S.A.), equipped with a refrigerated cooling system (RCS90). TRIOSTM software (version 3.1.5.3696) was used to analyze the results (TA Instruments, New Castle, DE, U.S.A.). Tzero aluminum pans (TA Instruments, New Castle, DE, U.S.A.) were used in all calorimetric studies. The empty pan was used as a reference and the mass of the reference pan and of the sample pans were taken into account. Dry nitrogen at $50 \mathrm{~mL} / \mathrm{min}$ was used as a purge gas through the DSC cell. Indium and n-octadecane standards were used to calibrate the DSC temperature scale; enthalpic response was calibrated with indium. The modulation parameters used were: $2{ }^{\circ} \mathrm{C} / \mathrm{min}$ heating rate, $40 \mathrm{~s}$ period and $1{ }^{\circ} \mathrm{C}$ amplitude. Calibration of heat capacity was done using sapphire. Samples were analyzed from 0 to 200 ${ }^{\circ} \mathrm{C}$.

\subsubsection{Preparation of Tablets}

To determine the degree of swelling, flat-faced tablets of $100 \mathrm{mg}$ polymer carrier were prepared by compressing the given amount of powders (C971, POZ $50 \mathrm{kDa}$, POZ $500 \mathrm{kDa}$, PMs, and IPCs) in a hydraulic press (Perkin Elmer, Waltham, MA, U.S.A.), equipped with flat-faced punches with $13 \mathrm{~mm}$ diameter (Pike Technologies, Madison, WI, U.S.A.) with a compression pressure of 6.24 MPa. For dissolution testing, $150 \mathrm{mg}$ biconvex tablets (100 mg 5-ASA and 50 
mg polymer carrier) with $6 \mathrm{~mm}$ diameter were prepared by compressing the given amount of the polymer carriers at $6.24 \mathrm{MPa}$ using a hydraulic press (Perkin Elmer, Waltham, MA, U.S.A.).

\subsubsection{Determination of the Degree of Swelling of Matrices}

Swelling was investigated under conditions, mimicking the gastro-intestinal tract (GIT): the first two hours in simulated gastric medium $(0.1 \mathrm{M} \mathrm{HCl} ; \mathrm{pH} 1.2)$, then four hours in simulated intestinal medium (phosphate buffer; pH 6.8).

\subsubsection{Gravimetric measurements}

The polymer matrices $(\mathrm{d}=13 \mathrm{~mm})$ were placed in a tarred basket (from USP I apparatus), which was immersed into a thermostatted bath at $37.0 \pm 0.5^{\circ} \mathrm{C}$ on IC control eco $18 \mathrm{c}\left(\mathrm{IKA}^{\circledR}\right.$ Werke $\mathrm{GmbH}$, Staufen, Germany). The volume of the medium was $100 \mathrm{~mL}$. The basket was removed from the medium every 15 min within the first hour and then every $30 \mathrm{~min}$; the tablets were carefully dried using a filter paper and weighed. The degree of swelling $(\mathrm{H}, \%)$ was calculated using the following equation:

$$
H_{\%}=\left(m_{2}-m_{1} / m_{1}\right) \times 100,
$$

where $m_{1}$ is the weight of the dry sample and $m_{2}$ is the weight of the swollen sample.

\subsubsection{Image analysis}

The polymer matrices $(\mathrm{d}=13 \mathrm{~mm})$ were placed into petri dishes with $40 \mathrm{~mL}$ of the medium preheated to $37.0 \pm 0.5^{\circ} \mathrm{C}$. The petri dishes with matrices were removed from thermostatted bath every 1 hour, placed on a graph paper and changes in the sizes of the matrices were measured.

\subsubsection{Release of mesalazine (5-ASA) from the polymer matrices in GIT mimicking conditions} The release of 5-ASA from the matrix tablets was performed under sink conditions at $37.0 \pm$ $0.1{ }^{\circ} \mathrm{C}$ using the USP I Apparatus (the off-line dissolution tester DT 828 with an auto sampler ASS-8, a fraction collector FRL 824 and a peristaltic pump ICP-8 (Erweka, Heusenstamm, Germany)). The basket rotation speed was $100 \mathrm{rpm}$ and the volume of the medium was 900 $\mathrm{mL}$. The release was investigated for $6 \mathrm{~h}$ under GIT mimicking conditions, where the $\mathrm{pH}$ of the release medium was gradually increased: $2 \mathrm{~h}$ in $0.1 \mathrm{M}$ hydrochloric acid $(\mathrm{pH}=1.2)$ and then in phosphate buffer solution $(\mathrm{pH}=6.8)$ until the end of experiment. Aliquots $(5 \mathrm{~mL})$ of solution were automatically taken at specific time intervals, and the volume of medium was 
made up to the original value by adding fresh dissolution medium. The amounts of 5-ASA released in the dissolution medium were determined by UV/Vis-spectrophotometry at $302 \mathrm{~nm}$ (at $\mathrm{pH}=1.2$ ) and $330 \mathrm{~nm}$ (at $\mathrm{pH}=6.8$ ), respectively (Lambda 25; Perkin-Elmer, Waltham, MA, U.S.A.). Results are given as the mean values of three determinations \pm standard deviations. Release rates (RR) were determined by calculating the slopes of the released 5-ASA (\%) vs time profiles in the first 120 min of experiment.

\section{Results and Discussion}

\section{Formation of interpolymer complexes in aqueous solutions}

Simple mixing of 0.002 unit-mol/L aqueous solutions of C971 and POZ (without adjustment of $\mathrm{pH}$ ) at room temperature results in immediate appearance of turbidity, which was used to estimate the compositions of IPCs formed. Figure 1 presents the turbidity data for the polymers mixed at different molar ratios. It is widely recognised that the maximal values of turbidity generally correspond to the compositions of IPC (Satoh et al, 1989; Takayama et al, 1990; Moustafine et al, 2006). POZ $50 \mathrm{kDa}$ exhibited greater ability to increase the turbidity of solution mixtures with the maximal values observed at [C971]:[POZ]=1.25:1 mol $/ \mathrm{mol}$. Similar trend is observed for POZ $500 \mathrm{kDa}$; however, its turbidity is significantly lower $(\mathrm{p}<0.005)$. POZ $5 \mathrm{kDa}$ exhibited much lower ability to increase the solution turbidity in mixtures with C971.

\section{(Figure 1 is here).}

It could be anticipated that these polymers should form 1:1 complexes, i.e. one unionised carboxylic group of C971 forms hydrogen bond with one proton-accepting nitrogen according to the proposed scheme (Figure 2). A deviation from 1:1 ratio observed in our experiments could be related to two factors: (1) a weakly cross-linked nature of C971, which results in steric hindrances and not complete availability of carboxylic groups of polyacid to interact with POZ; (2) under the $\mathrm{pH}$ conditions of this experiment not all carboxylic groups of C971 are nonionised and capable of forming hydrogen bonds with POZ. This result agrees with the previous studies of C971 - POZ complexes using gravimetric analysis (Ruiz-Rubio et al, 2018).

\section{(Figure 2 is here)}

Previously, Khutoryanskiy and co-workers (Mun et al, 2000; Nurkeeva et al, 2003; Khutoryanskiy et al, 2004a; Khutoryanskiy et al, 2004b; Nurkeeva et al, 2005; Zhunuspayev 
et al, 2008) have demonstrated that the complexation between poly(carboxylic acids) and nonionic polymers is facilitated under acidic conditions and formation of colloidal IPCs is typically observed below a certain critical $\mathrm{pH}$ of complexation $\left(\mathrm{pH}_{\text {crit }}\right) \cdot \mathrm{pH}_{\text {crit }}$ values were proposed as a criterion for the ability of a given pair of polymers to form hydrogen-bonded IPCs: greater $\mathrm{pH}_{\text {crit }}$ indicated a stronger ability of polymers to form complexes. To the best of our knowledge, the data on $\mathrm{pH}_{\text {crit }}$ of complexation involving poly(2-oxazolines) is still very limited in the literature. Su et al (2017) recently reported that the thickness of miltilayered films, formed using layer-by-layer deposition of poly(acrylic acid) (PAA) and POZ onto a solid substrate, showed a $\mathrm{pH}$ dependence, typical for hydrogen-bonded IPCs: a rapid increase in the film thickness is observed upon decrease in $\mathrm{pH}$ in the 3.5-4.0; above $\mathrm{pH} 4.0$ the films did not form. The authors assigned the $\mathrm{pH} 3.5-4.0$ to the critical $\mathrm{pH}$ of complexation between these polymers. In the present work the critical pHs were determined for Carbopol ${ }^{\circledR} 971$ - POZ complexes using turbidimetric technique. Figure 3 shows the dependence of solution turbidity of 1:1 polymer mixtures as a function of $\mathrm{pH}$. It is clearly seen that a decrease in solution $\mathrm{pH}$ results in a rapid increase in turbidity at $\mathrm{pH} 4.8 \pm 0.2$, when POZ $50 \mathrm{kDa}$ was used to form IPC. This is slightly larger than the $\mathrm{pH}_{\text {crit }}$ reported by Su et al (2017) for complexes of POZ $50 \mathrm{kDa}$ with PAA, but the discrepancy may be related to the difference in the methods used to determine $\mathrm{pH}_{\text {crit }}$ (film formation vs turbidimetric studies) and also the weakly cross-linked nature of Carbopol $^{\circledR} 971$ compared to PAA.

\section{(Figure 3 is here)}

POZ with lower (5 kDa) and larger (500 kDa) molecular weights show their $\mathrm{pH}_{\text {crit }}$ around 4.24.5 (no significant difference between $\mathrm{pH}_{\text {crit }}$ for $5 \mathrm{kDa}$ and $500 \mathrm{kDa}(\mathrm{p}>0.05)$, but significantly lower than $\mathrm{pH}_{\text {crit }}$ for $50 \mathrm{kDa}(\mathrm{p}<0.05)$ ). It is well known from the literature (Mun et al, 2000; Nurkeeva et al, 2003; Khutoryanskiy et al, 2004a; Khutoryanskiy et al, 2004b; Nurkeeva et al, 2005 ) that increase in molecular weight of the polymers typically leads to increase in $\mathrm{pH}_{\text {crit. }}$ An anomalous lower complexation ability of POZ $500 \mathrm{kDa}$ observed in experiments presented in Figure 1 (lower turbidity values) and also lower $\mathrm{pH}_{\text {crit }}$ values compared to $\mathrm{POZ} 50 \mathrm{kDa}$ (Figure 2) is possibly related to extremely large length of POZ $500 \mathrm{kDa}$ macromolecules that approach so-called upper limit in molecular weights of polymers, previously reported by Bekturov and Bimendina (1981).

A comparison of $\mathrm{pH}_{\text {crit }}$ values, previously reported for complexes of PAA and poly(N-vinyl pyrrolidone) $\mathrm{pH}_{\text {crit }}=4.85 \pm 0.05$, poly(methyl vinyl ether) $\mathrm{pH}_{\text {crit }}=4.85 \pm 0.05$, polyacrylamide 
$\mathrm{pH}_{\text {crit }}=3.00 \pm 0.05$, poly(ethylene oxide) $\mathrm{pH}_{\text {crit }}=2.88 \pm 0.05$, poly (vinyl alcohol) $\mathrm{pH}_{\text {crit }}=2.67 \pm$ 0.05 and some other polymers (Khutoryanskiy et al, 2004a), with the values determined for POZ in the present work allows to conclude that poly(2-ethyl-2-oxazoline) exhibits strong complexation ability. This ability to form IPCs is comparable with poly(N-vinyl pyrrolidone) and poly(methyl vinyl ether). It should be noted that in the current study we used polymer concentrations of 0.01 unit-mol/L similar to the measurements reported by Khutoryanskiy et al (2004a); however, the difference in the two studies is in the use of Carbopol ${ }^{\circledR} 971$ (weakly cross-linked PAA, $3000 \mathrm{kDa}$ ) and linear PAA $450 \mathrm{kDa}$.

In order to get an insight into the changes in the structure of IPCs at different pHs transmission electron microscopy (TEM) was used (Figure 4a). This experiment provides an excellent opportunity to see the evolution of IPC structure upon gradual decrease in solution $\mathrm{pH}$. At $\mathrm{pH} 4.79$, which is very close to $\mathrm{pH}_{\text {crit }}$ the structure of IPC looks like a network of fibrous material with the presence of some very small particles $(18 \pm 6 \mathrm{~nm})$. Upon decrease in $\mathrm{pH}$ to 4.54 these particles become larger and denser $(41 \pm 4 \mathrm{~nm})$, but still are surrounded and connected to each other by fibrous material, which is possibly made of not fully complexed macromolecules. Under strongly acidic conditions the dense particles of IPC are fully formed; they are not stabilised by uncomplexed macromolecules and their size reaches $649 \pm 185 \mathrm{~nm}$ $(\mathrm{pH} 2.14)$ and $513 \pm 92 \mathrm{~nm}(\mathrm{pH} 2.50)$. Very similar structural changes at different $\mathrm{pHs}$ were reported previously for the IPC formed by PAA and methylcellulose (Khutoryanskaya et al, 2007). The proposed mechanism of IPC formation at different pHs is shown in Figure $\mathbf{4 b .}$

(Figure 4 is here)

\section{Physicochemical studies in solid state}

\subsection{Fourier transform infrared spectroscopy (ATR-FTIR)}

ATR-FTIR spectrum of pure POZ independently from its molecular weight is characterized by the presence of a stretching band of amide I at $1635 \mathrm{~cm}^{-1}$. For C971, the band corresponding to the self-associated carboxylic group $(\mathrm{COOH})$ is located at $1703 \mathrm{~cm}^{-1}$ (Nguyen et al., 2016; Ruiz-Rubio et al., 2018; Garipova et al, 2018). Clearly, the presence of POZ and C971 in the spectrum of the polymer mixture (PM) is indicated by their characteristic peaks with high intensities, such as the peak of the carboxyl stretching band of C971 $\left(1705 \mathrm{~cm}^{-1}\right)$ and a "shoulder" of amide I of POZ $\left(1635 \mathrm{~cm}^{-1}\right)$. In the IPC, a shift of the C=O bands could be observed to $1720 \mathrm{~cm}^{-1}$, while the amide I band shifts to $1600 \mathrm{~cm}^{-1}$. These bands are related to hydrogen bond formation between carboxyl groups of C971 and amide groups of POZ. 


\subsection{Thermal analysis}

Figure 6(a, b) shows the DSC thermograms of C974, POZ $50 \mathrm{kDa}(\mathrm{a}), \mathrm{POZ} 500 \mathrm{kDa}(\mathrm{b})$, their PMs and IPCs. Carbopol 974 presents a $T g$ at $132.6{ }^{\circ} \mathrm{C}$, whereas the $T g$ of POZ 50 and POZ $500 \mathrm{kDa}$ are detected at 51.7 and $56.2^{\circ} \mathrm{C}$, respectively. The presence of two unchanged $T g$ values in the PM prepared from C971 and both POZ samples (50 and $500 \mathrm{kDa}$ ) is indicating a phase separation of the polymers, i.e., confirmed that they were not molecularly miscible (Moustafine et al., 2011, 2013). The IPCs of these polymers present an intermediate glass transition of $128.3-128.9^{\circ} \mathrm{C}$, similar to the changes observed in other IPCs and IPECs formed via hydrogen and ionic bonding, respectively (Khutoryanskiy et al, 2004b; Khutoryanskiy et al, 2004c; Ruiz-Rubio et al., 2018; Mustafin, 2011; Mustafin et al., 2011, 2015; Moustafine et al., 2011, 2013).

\section{(Figure 6 is here).}

\section{Swelling properties}

Swelling of the matrices in the media mimicking the gastrointestinal tract indicate that the compacts based on POZ $50 \mathrm{kDa}$ and POZ $500 \mathrm{kDa}$ completely dissolved at the end of the first hour (Figure 7). Matrices from C971 showed the highest values in swelling estimated by both methods (Figure 8a, b). During swelling, the matrices separated into two clearly visible layers, transparent external gel and non-hydrated white core. We believe that the external layer is formed due to the hydration of macromolecules with ionized carboxyl groups, while the core is still containing the chains with protonated $\mathrm{COOH}$ groups. Physical mixtures with POZ 50 $\mathrm{kDa}(\mathrm{PM}-1)$ and POZ $500 \mathrm{kDa}$ (denoted as PM-2) show the values of matrix size similar to C971, but characterized by gradual release of POZ, localized in the external layer of the matrices in buffer medium. On the contrary, the swelling profiles of PM-1 and PM-2 are similar to each other only in acidic medium and have different character in the buffer at $\mathrm{pH} 6.8$. The PM matrices based on POZ $50 \mathrm{kDa}$ have two times lower swelling index in the buffer medium, compared to the swelling profile of PM with POZ $500 \mathrm{kDa}$. Moreover, in the case of two PM samples containing POZ with different molecular weight a stable swelling profile was observed only in the case of PM-1, relatively independent of the medium. PM-2 had a swelling profile similar to the matrices composed of pure C971, but with three times lower swelling degree as compared to the pure Carbopol ${ }^{\circledR}$. These observations are believed to be resulting from hydrogen bonding effect between these polymers, which was probably happened within PM matrices under acidic conditions. 
Upon swelling, the polycomplex matrices showed the smaller dimensions, which means lower swelling ability. Additionally, the swelling profiles of IPC matrices showed similar character, but different swelling ability: in case of IPC formed with POZ $500 \mathrm{kDa}$ the maximal swelling was approximately two times greater compared to the IPC with POZ $50 \mathrm{kDa}$. So, only PMs and IPCs with POZ $50 \mathrm{kDa}$ show the most stable profiles with the lowest swelling degree, but in case of PM it has three times lower degree of swelling. The formulations consisting of proton-accepting non-ionic polymers (PVP, PEO, HPMC, HPC, MC, etc.) and proton-donating polycarboxylic acids - (polyacrylic / polymethacrylic acids, Carbopol ${ }^{\circledR}$ grades) could form IPCs under acidic $\mathrm{pH}$ and their swelling and drug release properties are controlled by threedimensional network structure, which was formed as a result of complex formation between the polymers following water penetration into the matrix (Takayama and Nagai, 1987; Satoh et al., 1989; Ozeki et al., 1998a, 1998b, 1999, 2000, 2005; Tan et all., 2001).

(Figure 8 is here)

For further analysis the matrices with gel layers and non-hydrated cores were taken out from the dissolution baskets in GIT- mimicking media at different time intervals ( 0,2 and $6 \mathrm{~h}$ ); their gel layers and non-hydrated cores were physically separated and freeze-dried. The algorithm of their physicochemical analysis is schematically illustrated in Figure 9.

(Figure 9 is here)

ATR-FTIR spectra (Figure 10) were recorded to gain a deeper insight into the spatial distribution of the macromolecules and their interactions in the matrix tablets containing PM based on POZ and C971 following their hydration. In the intact interpolymer complex, a shift of the $\mathrm{C}=\mathrm{O}$ bands is observed to $1720 \mathrm{~cm}^{-1}$, while the amide I band shifts to $1600 \mathrm{~cm}^{-1}$. These bands are related to hydrogen bonding between carboxyl groups of C971 and amide groups of POZ.

(Figure 10 is here)

During the first $2 \mathrm{~h}$ in $\mathrm{pH} \mathrm{1.2,} \mathrm{the} \mathrm{monolith} \mathrm{polycomplex} \mathrm{matrix} \mathrm{has} \mathrm{the} \mathrm{composition}$ similar to IPC without any differences in FTIR spectra and $T g$ values; however, there is a slight change in the composition of IPC from C971/POZ 1.4:1 into 1.5:1. During the swelling for 4 $\mathrm{h}$ in the buffer solution ( $\mathrm{pH}$ 6.8), the gel layer is formed that is composed of mainly $\mathrm{C} 971$ in its ionized hydrated form (appearance of a new band at $1557 \mathrm{~cm}^{-1}$ ). In contrast, the amount of 
POZ (according to the elemental analysis results, presented in Table 1) in the gel layer within $4 \mathrm{~h}$ (pH 6.8) is decreased and reached 2.7:1 C971/POZ molar ratio. This is also evidenced by the presence of amide I stretching at $1633 \mathrm{~cm}^{-1}$ and the individual $T g$ value assigned to the pure $\mathrm{POZ}$ at $45.1 \pm 0.8^{\circ} \mathrm{C}$. Moreover, an increase in the $T g$ values from $125.2 \pm 0.3$ to $127.9 \pm 0.7{ }^{\circ} \mathrm{C}$ and observed shifts of the characteristic bands at 1600 to $1606 \mathrm{~cm}^{-1}$ are related to the presence of hydrogen bonds between amide groups of POZ and carboxyl groups of C971; however, some segments of the IPC contain partly ionized $\mathrm{COO}^{-}$groups leading to dissociation of some interpolymer bonds. On the contrary, the non-hydrated core of IPC matrices still consists of the polycomplex structure, whose composition is close to the original IPC and IPC monolith matrix taken after its exposure to the acidic medium ( $\mathrm{pH}$ 1.2). This result agrees with our studies using TEM technique.

\section{(Table 1 is here).}

The swelling behavior of PMs was found to be completely different from the tablets based on IPCs. Clearly, POZ and C971 dispersed uniformly in the intact tablet prior to hydration, as reflected by the presence of their characteristic peaks with high intensities in the spectrum of PM, such as the peak of the carboxyl stretching band of C971 $\left(1704 \mathrm{~cm}^{-1}\right)$ and a "shoulder" of amide I of POZ $\left(1633 \mathrm{~cm}^{-1}\right)$. According to above discussed mechanism of IPCs formation and also the literature data (Takayama and Nagai, 1987; Satoh et al., 1989; Ozeki et al., 1998a, 1998b; Tan et al., 2001; Zhang et al., 2016a, 2016b; Yusif et al., 2016; Szakonyi and Zelko, 2016, Nguyen et al., 2016), the passage of the tablets through pH 1.2 media facilitates strong interaction between the polymers. However, the spectral and thermal analysis results did not provide any evidence for the complexation under these conditions: the band corresponding to the self-associated carboxylic groups $(\mathrm{COOH})$ located at $1704 \mathrm{~cm}^{-1}$ showed a very minor shift to $1707 \mathrm{~cm}^{-1}$ and the presence of amide I stretching was observed at $1622 \mathrm{~cm}^{-}$ 1; $T g$ values at $51.7 \pm 0.9^{\circ} \mathrm{C}$ and $131.9 \pm 0.8^{\circ} \mathrm{C}$ observed are assigned to the pure POZ $50 \mathrm{kDa}$ and C971, respectively. Moreover, some amount of pure POZ $50 \mathrm{kDa}$ is leaching from the matrices, so the composition of mixture is changed from C971/POZ 1.4:1 to 2.2:1.

During $4 \mathrm{~h}$ swelling of PM-1 in $\mathrm{pH}$ 6.8, the matrix composition becomes different to the composition of IPC. As it is seen from the data presented in Fig. 10 and Table 1, PM-1 with POZ $50 \mathrm{kDa}$ tablets completely transformed to the transparent gel with maximal gelforming capacity, which is clearly visible compared to pure C971 matrix. Additionally, in the ATR-FTIR spectrum of the freeze-dried gel layer (formed during $4 \mathrm{~h}$ swelling) the peak at 
$1704 \mathrm{~cm}^{-1}$, corresponding to the carboxylic groups of C971, disappeared and was replaced by a new band at $1556 \mathrm{~cm}^{-1}$ assigned to the carboxylate ion $\left(\mathrm{COO}^{-}\right)$. These findings indicated that the carboxylic groups in C971 were ionized when it came to contact with pH 6.8 buffer. This is also confirmed by higher $\mathrm{Tg}$ value $\left(145.7 \pm 0.7{ }^{\circ} \mathrm{C}\right)$ assigned to the ionized C971 that is in good agreement with literature (Gomez-Carracedo et al., 2004). POZ was also present in the gel layer: the peak at $1630 \mathrm{~cm}^{-1}$ corresponding to the amide I stretching and somehow higher $T g$ value $\left(59.4 \pm 0.9^{\circ} \mathrm{C}\right.$ ) were assigned to POZ. At $4 \mathrm{~h}$ in $\mathrm{pH} 6.8$ (with a total swelling time of $6 \mathrm{~h}$ ), the gel layer lost substantial amount of POZ, as confirmed by remarkable change in C971/POZ composition from 1.4:1 to 5.8:1. So, the leaching of pure POZ from the gel layer is evident. The diffusion of POZ from the gel layer led to increase in the diffusional path length of the matrix, by which the drug release rate could be sustained (Ruiz-Rubio et al., 2018).

POZ was predominantly present in the non-hydrated core at $4 \mathrm{~h}$ of swelling, evidenced by a strong band at $1627 \mathrm{~cm}^{-1}$. In particular, the peak at $1704 \mathrm{~cm}^{-1}$ assigned to the selfassociated carboxylic groups of C971 exhibited a gradual increase in the intensity with time and shifted to $1715 \mathrm{~cm}^{-1}$ corresponding to the carbonyl $\mathrm{C}=\mathrm{O}$ stretching vibrations bands (Takayama and Nagai, 1987; Satoh et al., 1989; Ozeki et al., 1998a, 1998b, 1999, 2000, 2005). At $6 \mathrm{~h}$ of swelling, the non-hydrated core was completely transformed into hydrated form: $\mathrm{Tg}$ value assigned to $\mathrm{POZ}$ at $45.2 \pm 0.7^{\circ} \mathrm{C}$ and slightly ionized $\mathrm{C} 971$ at $140.4 \pm 0.9^{\circ} \mathrm{C}$. Composition of the material after complete hydration also changed from C971/POZ 1.4:1 to 2.4:1.

In addition, a frequency shift in the peak assigned to the amide I stretching group of POZ in the gel layer and non-hydrated core at $6 \mathrm{~h}$ of swelling changed from $1633 \mathrm{~cm}^{-1}$ to 1600 $\mathrm{cm}^{-1}$ and appearance of characteristic $T g$ value at $125.2 \pm 0.3{ }^{\circ} \mathrm{C}$, typical for strong hydrogen bonding between POZ and C971 were not observed.

\section{Drug release studies}

Mesalazine (5-ASA) is an anti-inflammatory drug that is used to treat some conditions of gastrointestinal tract, for example, inflammatory bowel disease (Quinteros et al, 2010). 5-ASA was used in this work as a model drug. The release of 5-ASA from the matrices was evaluated under GIT mimicking conditions. Figure 11 shows the dissolution profiles from the matrices based on C971 as well as their IPCs and PMs with POZ. Drug released faster from the matrices composed of pure POZ (RR=0.8513\%/min and $0.6665 \% / \mathrm{min}$ for 50 and $500 \mathrm{kDa} \mathrm{POZ}$, respectively) and IPCs $(\mathrm{RR}=0.3676 \% / \mathrm{min}$ and $0.9016 \% / \mathrm{min}$ for 50 and $500 \mathrm{kDa} \mathrm{POZ}$, respectively) compared to pure C971 (RR=0.1644\%/min) and PMs $(0.1017 \% / \mathrm{min}$ and 0.1610 

release in acidic medium compared to all other samples. Additionally, the whole release process for this IPC is finished during the first $2 \mathrm{~h}$ in acidic medium. Understanding of this observation could come from our TEM results and evaluation of the swelling data. According to TEM data, under strongly acidic conditions the dense IPC particles with POZ $500 \mathrm{kDa}$ are formed and their size reaches $649 \pm 185 \mathrm{~nm}(\mathrm{pH} 2.14)$. Thus, in our release media $(\mathrm{pH} 1.2)$ the IPC particles became bigger that leads to formation of greater pores in the system compared to the IPC formed with POZ $50 \mathrm{kDa}$. Further evidence comes from the swelling properties of polycomplex matrices. The swelling index, estimated by two methods shows that IPC with POZ $500 \mathrm{kDa}$ matrices exhibits greater swelling at $\mathrm{pH} 1.2$ compared to IPC with POZ $50 \mathrm{kDa}$ due to the formation of compact monolith structure with much lower porosity. Moreover, the observed phenomena also indicate that POZ is predominantly present on the surface of microgels formed from weakly cross-linked C971.

Despite that diffusion of POZ $500 \mathrm{kDa}$ from non-hydrated core to the gel layer may be slower due to its high molecular weight, compared to PM made from POZ $50 \mathrm{kDa}$, drug release process may proceed differently. It is known that hydrogen bonds in IPC matrices help increasing the gel strength to improve the release-retarding capacity of polymer matrix (Tan et al., 2001; Zhang et al., 2015, 2016; Yusif et al., 2016; Szakonyi and Zelko, 2016, Nguyen et al., 2016). Thus, in case of some proton-accepting non-ionic polymers (e.g. hydroxypropyl cellulose, HPC) and polycarboxylic acids (PAA or Carbopols), which could form IPC in acidic pH region and of course, in typical dissolution media, the release of drugs is controlled by the threedimensional network structure, which is affected by complex formation between these polymers following water penetration into the matrix (Satoh et al, 1989). If it can happen we will see a significant retardation of drug release, but mostly in the case of PM matrices and not for IPCs.

443 The release rate of 5-ASA greatly decreases when the matrix was composed of PM. According 444 to the abovementioned explanation of the swelling results, the decrease in the release rate in this case could be due to the complexation between the polymers, which has happened inside the matrix during penetration of dissolution media, resulting in the formation of threedimensional network. This leads to the formation of insoluble fibers in the matrix structure, which significantly retard the drug release process. 
Based on these results, the following explanation of drug release from IPC system could be proposed: in acidic medium, macromolecules of IPC swell significantly and 5-ASA partially dissolves from the surface of the matrix. The remaining amount of the undissolved drug after its transfer to another medium could continuously dissolve and diffuse from the swollen gel layer, that acts as a driving force for 5-ASA molecules. On the contrary, at pH 6.8, hydrogen bonds between POZ and C917 are dissociated due to gradual ionization of $\mathrm{COOH}$ groups of C971 and 5-ASA, leading to destruction of interpolymer contacts (according to FTIR and mDSC data). Together with release of free POZ macromolecules (according to elemental analysis data) this facilitates dissolution of 5-ASA. Hence, C971 was responsible for sustaining drug release during the first $2 \mathrm{~h}$ to prevent the initial burst release. POZ then diffused gradually from the non-hydrated core to the gel layer, decreasing the gel strength and resulting in the gradual destruction of hydrogen bonding interaction between POZ and C971. For this reason, the rate of 5-ASA release in this polymer system (mixture-loaded matrix) progressively increased at latter stages.

Additionally, drug release from different matrices could also be affected by specific interactions of mesalazine with C971 and POZ. As 5-ASA contains both proton-donating and proton-accepting groups in its structure, its interaction with Carbopols via ionic contacts (Quinteros et al, 2011) and with POZ via hydrogen bonding could not be ruled out completely. $\mathrm{pH}$ of dissolution medium is also expected to have effect on these interactions.

\section{Conclusions}

471 Formation of interpolymer complexes between Carbopol ${ }^{\circledR} 971$ and poly(2-ethyl-2-oxazoline) of different molecular weights has been studied in aqueous solutions at different pHs. It was established that interpolymer hydrogen bonding is responsible for this complex formation; these interactions are possible only under acidic conditions. The evolution in the structure of the products of interpolymer interaction was studied in solutions with different $\mathrm{pH}$. Upon a gradual decrease in solution $\mathrm{pH}$ the polymer mixtures evolved from completely non-interacting macromolecules to initial interpolymer associates, which then converted into primary compact IPC particles that were eventually transformed into spherical aggregates. Tablets were then prepared from interpolymer complexes and physical mixtures of Carbopol ${ }^{\circledR} 971$ and poly(2ethyl-2-oxazoline) with and without a model drug (mesalazine). The structure of these materials was evaluated using FTIR and differential scanning calorimetry methods as well as swelling studies in the media mimicking conditions of gastrointestinal tract. It was established 
that the state of the polymers in the mixture and their swelling behavior is affected by the possibility of the complexation between them. The release of mesalazine from these tablets is also strongly influenced by the presence of interpolymer complexation. To the best of our knowledge, this is the first time when interpolymer complexes between Carbopol ${ }^{\circledR} 971$ and poly(2-ethyl-2-oxazoline) were used to prepare solid dosage forms for gastrointestinal drug delivery. Potentially future research could compare poly(2-ethyl-2-oxazoline) with other nonionic polymers capable of forming interpolymer complexes with Carbopol $^{\circledR} 971$ (e.g. polyvinylpyrrolidone and polyethylene oxide) to establish if it could offer any advantages as a novel pharmaceutical excipient.

\section{Acknowledgments}

This work was, in part, financially supported by the Russian Foundation for Basic Research (RFBR) and the Russian Science Foundation (RSF) in the framework of projects 16-04-01692 (to R.I.M.) and 14-15-01059 (to R.I.M., A.S.V.), respectively. The authors acknowledge the Ministry of Education and Science of the Republic of Tatarstan (Russia) for "Algarysh" grant supporting V.V.K. visits to Kazan State Medical University. Chemical Analysis Facility (University of Reading) and Dr Peter Harris are gratefully acknowledged for access to transmission electron microscopy and for provision of technical help. The authors are also grateful to Mr Shamil Nasibullin for his technical help with thermal analysis.

\section{References}

Ambreen J., Siddiq M. (2014). Effect of arm number of poly(acrylic acid) on cloud point temperature of poly(2-ethyl-2-oxazoline). J. Polym. Res. 21, 608.

Bekturov E.A., Bimendina L.A. (1981). Interpolymer complexes. Adv. Polym. Sci. 41, 99-147.

Bludau H., Czapar A.E., Pitek A.S., Shukla S., Jordan R., Steinmetz N.F. (2017). POxylation as an alternative stealth coating for biomedical applications. Eur. Polym. J., 88, 679-688.

Christova D., Velichkova R., Loos W., Goethals E.J., Du Prezb F. (2003). New thermoresponsive polymer materials based on poly(2-ethyl-2-oxazoline) segments. Polymer, 44, $2255-2261$. 
512 Claeys B., Vervaeck A., Vervaet C., Remon J.P., Hoogenboom R., De Geest B.G. (2012). 513 Poly(2-ethyl-2-oxazoline) as matrix excipient for drug formulation by hot melt extrusion and 514 injection molding. Macromol. Rapid Commun., 33, 1701-1707.

515 Dai J., Goh S.H., Lee S.Y., Siow K.S. (1994). Complexation between poly(2516 hydroxypropylmethacrylate) and three tertiary amide polymers. J. Appl. Polym. Sci. 53, 837517845.

518 de la Rosa V.R. (2014). Poly(2-oxazoline)s as materials for biomedical applications. J. Mater. 519 Sci.: Materials in Medicine, 25, 1211-1225.

520 Diehl C., Schlaad H. (2009). Thermo-responsive polyoxazolines with widely tuneable LCST. 521 Macromol Biosci. 9, 157-161.

522 Fael H., Rafols C., Demirel A.L. (2018). Poly(2-ethyl-2-oxazoline) as an alternative to 523 poly(vinylpyrrolidone) in solid dispersions for solubility and dissolution rate enhancement of 524 drugs. J. Pharm. Sci. 107, 2428-2438.

525 Farrugia B.L, Kempe K., Schubert U.S., Hoogenboom R., Dargaville T.R. (2013). Poly(2526 oxazoline) Hydrogels for Controlled Fibroblast Attachment. Biomacromolecules, 14, 27245272732.

528 Filippov S.K., Verbraeken B., Konarev P.V., Svergun D.I, Angelov B., Vishnevetskaya N.S., 529 Papadakis C.M., Rogers S., Radulescu A., Courtin T., Martins J.C., Starovoytova L., Hruby 530 M., Stepanek P., Kravchenko V.S., Potemkin I.I., Hoogenboom R. (2017). Block and Gradient 531 Copoly(2-oxazoline) Micelles: Strikingly Different on the Inside. J. Phys. Chem. Lett., 8, $532 \quad 3800-3804$.

533 Garipova V.R., Gennari C.G.M., Selmin F., Cilurzo F., Moustafine R.I. (2018). Mucoadhesive 534 interpolyelectrolyte complexes for the buccal delivery of Clobetasol, Polymers, 10(1), 85.

535 Gomez-Carracedo A., Alvarez-Lorenzo C., Gomez-Amoza J.L., Concheiro A. (2004). Glass 536 transitions and viscoelastic properties of Carbopol ${ }^{\circledR}$ and Noveon ${ }^{\circledR}$ compacts, Int. J. Pharm. 274, 537 233-243.

538 Hoogenboom R. (2009). Poly(2-oxazoline)s: A Polymer Class with Numerous Potential 539 Applications. Angew. Chem. Int. Ed., 48, 7978 - 7994

540 Hoogenboom R., Schlaad H. (2017). Thermoresponsive poly(2-oxazoline)s, polypeptoids, and 541 polypeptides. Polym. Chem., 8, 24-40. 

K. (2010). Polyoxazoline thermoresponsive micelles as radionuclide delivery systems. Macromol Biosci. 10, 916-924.

Isasi J.R., Meaurio E., Cesteros C., Katime I. (1996). Miscibility and specific interactions in blends of poly(2-ethyl-2-oxazoline) with hydroxylated polymethacrylates. Macromol. Chem.

547 Phys. 197, 641-649. A.B., Tencova A.I., Kabanov V.A. (1991). Applying interpolymer complexes in pharmacy. Farmatsiya 60(1), 67-72.

551 Kharlampieva E., Kozlovkaya V., Sukhishvili S.A. (2009). Layer-by -Layer Hydrogen-Bonded Polymer Films: From Fundamentals to Applications. Adv. Mater., 21, 3053-3065

Khutoryanskaya O.V., Williams A.C., Khutoryanskiy V.V. (2007). pH-mediated interactions between poly(acrylic acid) and methylcellulose in the formation of ultrathin multilayered hydrogels and spherical nanoparticles, Macromolecules, 40, 7707-7713.

556 Khutoryanskiy V.V., Mun G.A., Nurkeeva Z.S., Dubolazov A.V. (2004a). pH- and salts557 effects on interpolymer complexation via hydrogen bonding in aqueous solutions, Polym. Int., 558 53, 1946-1950.

559 Khutoryanskiy V.V., Dubolazov A.V., Nurkeeva Z.S., Mun G.A. (2004b). pH-effects in the 560 complex formation and blending of poly(acrylic acid) with poly(ethylene oxide), Langmuir 20, 561 9, 3785-3790.

562 Khutoryanskiy V.V., Cascone M.G., Lazzeri L., Barbani N., Nurkeeva Z.S., Mun G.A., 563 Dubolazov A.V. (2004c). Morphological and thermal characterization of interpolymer 564 complexes and blends based on poly(acrylic acid) and hydroxypropylcellulose, Polym. Int. 53, $565307-311$.

566 Khutoryanskiy V.V. (2007). Hydrogen-bonded interpolymer complexes as materials for 567 pharmaceutical applications. Int. J. Pharm. 334, 15-26.

568 Khutoryanskiy V.V. (2018). Beyond PEGylation: alternative surface-modification of 569 nanoparticles with mucus-inert biomaterials, Advanced Drug Delivery Reviews, 124, 140-149. 
570 Kim C., Lee S.C., Kwon I.C., Chung H., Jeong S.Y. (2002). Complexation of poly(2-ethyl-2571 oxazoline)-block-poly(e-caprolactone) micelles with multifunctional carboxylic acids. 572 Macromolecules, 35, 193-200.

573 Lehner R., Liu K., Wang X., Wolf M., Hunziker P. (2017). A comparison of plasmid DNA 574 delivery efficiency and cytotoxicity of two cationic diblock polyoxazoline copolymers. 575 Nanotechnology 28, 175602, 1-11.

576 Lorson T., Lübtow M.M., Wegener E., Haider M.S., Borova S., Nahm D., Jordan R., Sokolski577 Papkov M., Kabanov A.V., Luxenhofer R. (2018). Poly(2-oxazoline)s based biomaterials: A 578 comprehensive and critical update. Biomaterials. 178, 204-280.

579 Luxenhofer R., Han Y., Schulz A., Tong J., He Z., Kabanov A.V., Jordan R. (2012). Poly(2580 oxazoline)s as polymer therapeutics. Macromol Rapid Commun. 33, 1613-1631.

Mansfield E.D.H., de la Rosa V.R., Kowalczyk R.M., Grillo I., Hoogenboom R., Sillence K., Hole P., Williams A.C., Khutoryanskiy V.V. (2016). Side chain variations radically alter the diffusion of poly(2-alkyl-2-oxazoline)s functionalised nanoparticles through a mucosal barrier, Biomat. Sci., 4, 1318-1327.

Mansfield E.D.H., Sillence K., Hole P., Williams A.C., Khutoryanskiy V.V. (2015). POZylation; a new approach to enhance nanoparticle diffusion through mucosal barriers, Nanoscale, 7, 13671-13679.

Mero A., Pasut G., Via L.D., Fijten M.W.M., Schubert U.S., Hoogenboom R., Veronese F.M. 589 (2008). Synthesis and characterization of poly(2-ethyl 2-oxazoline)-conjugates with proteins and drugs: Suitable alternatives to PEG-conjugates? J. Control. Release, 125, 87-95.

Moustafine R.I., Bobyleva V.L., Bukhovets A.V., Garipova V.R., Kabanova T.V., Kemenova V.A., Van den Mooter G., (2011). Structural transformations during swelling of polycomplex matrices based on countercharged (meth)acrylate copolymers (Eudragit ${ }^{\circledR}$ E PO/Eudragit ${ }^{\circledR} \mathrm{L}$ 100-55). J. Pharm. Sci., 100(3), 874-885.

Moustafine R.I., Bukhovets A.V., Sitenkov A.Y., Kemenova V.A., Rombaut P., Van den 596 Mooter G. (2013). Eudragit ${ }^{\circledR}$ E PO as a complementary material for designing oral drug delivery systems with controlled release properties: comparative evaluation of new interpolyelectrolyte complexes with countercharged Eudragit ${ }^{\circledR}$ L100 copolymers. Mol. Pharm., 10(7), 2630-2641. 
600

601

602

603

604

605

606

607

608

609

610

611

612

613

614

615

616

617

618

619

620

621

622

623

624

625

626

627

628

Moustafine R.I., Zaharov I.M., Kemenova V.A. (2006). Physicochemical characterization and drug release properties of Eudragit ${ }^{\circledR}$ EPO/Eudragit ${ }^{\circledR}$ L 100-55 interpolyelectrolyte complexes. Eur. J. Pharm. Biopharm. 63, 26-36.

Mun G.A., Nurkeeva Z.S., Khutoryanskiy V.V., Bitekenova A.B. (2000). Effect of copolymer composition on interpolymer complex formation of (co)polyvinyl ethers with polyacrylic acid in aqueous and organic solutions, Macromol. Rapid Commun., 21, 381-384.

Mustafin R.I. (Moustafine R.I.), (2011). Interpolymer combinations of chemically complementary grades of Eudragit copolymers: A new direction in the design of peroral solid dosage forms of drug delivery systems with controlled release (review). Pharm. Chem. J. 45, 285-295.

Mustafin R.I. (Moustafine R.I.), Bukhovets A.V., Sitenkov A.Yu., Garipova V.R., Kemenova V.A., Rombaut P., Van den Mooter G. (2011). Synthesis and characterization of a new carrier based on Eudragit ${ }^{\circledR} \mathrm{EPO} / \mathrm{S} 100$ interpolyelectrolyte complex for controlled colon-specific drug delivery. Pharm. Chem. J. 45, 568-574.

Mustafin R.I. (Moustafine R.I.), Semina I. I., Garipova V.R., Bukhovets A.V., Sitenkov A.Yu., Salakhova A.R., Gennari C.G.M., Cilurzo F. (2015). Comparative study of polycomplexes based on Carbopol ${ }^{\circledR}$ and oppositely charged polyelectrolytes as a new oral drug delivery system. Pharm. Chem. J. 49(1), 1-6.

Nguyen H.V., Nguyen V.H., Lee B.-J. (2016). Dual release and molecular mechanism of bilayered aceclofenac tablet using polymer mixture. Int. J. Pharm., 515, 233-244.

Nurkeeva Z.S., Mun G.A., Dubolazov A.V., Khutoryanskiy V.V. (2005). pH-effects on the complexation, miscibility and radiation-induced cross-linking in poly(acrylic acid)-poly(vinyl alcohol) blends, Macromol. Biosci., 5, 424-432.

Nurkeeva Z.S., Mun G.A., Khutoryanskiy V.V., Bitekenova A.B., Dubolazov A.V., Esirkegenova S.Zh. (2003). pH effects in the formation of interpolymer complexes between poly(N-vinylpyrrolidone) and poly(acrylic acid) in aqueous solutions, Eur. Phys. J. E, 10, 6568.

Ozeki T., Yuasa H., Kanaya Y. (1998a). Control of medicine release from solid dispertion through poly(ethylene oxide)-carboxyvinyl polymer interaction. Int. J. Pharm., 165, 239-244. 
629

630

631

632

633

634

635

636

637

638

639

640

641

642

643

644

645

646

647

648

649

650

651

652

653

654

655

656

657

Ozeki T., Yuasa H., Kanaya Y. (1998b). Mechanism of medicine release from solid dispersion composed of poly(ethylene oxide)-carboxyvinylpolymer interpolymer complex and $\mathrm{pH}$ effect on medicine release. Int. J. Pharm. 171, 123-132.

Ozeki T., Yuasa H., Kanaya Y. (1999). Controlled release from solid dispersion composed of poly(ethylene oxide)-carboxyvinylpolymer interpolymer complex by varying molecular weight of poly(ethylene oxide). J. Control. Release 58, 87-95.

Ozeki T., Yuasa H., Kanaya Y. (2000). Controlled release from solid dispersion composed of poly(ethylene oxide)-carboxyvinylpolymer interpolymer complex with various cross-linking degree of Carbopol®. J. Control. Release 63, 287-295.

Ozeki T., Yuasa H., Okada H. (2005). Controlled release of drug via methylcellulosecarboxyvinylpolymer interpolymer complex solid dispersion. AAPS PharmSciTech. 6, e231e236.

Policianova O., Brus J., Hruby M., Urbanova m., Zhigunov A., Kredatusova J., Kobera L. (2014). Structural diversity of solid dispersions of acetylsalicylic acid as seen by solid-state NMR. Mol. Pharm., 11, 516-530.

Quinteros D.A., Manzo R.H., Allemandi D.A. (2010). Design of a colonic delivery system based on cationic polymethacrylate (Eudragit E100)-mesalamine complexes. Drug Delivery, 17(4): 208-213.

Quinteros D.A., Manzo R.H., Allemandi D.A. (2011). Interaction between Eudragit E100 and anionic drugs: Addition of anionic polyelectrolytes and their influence on drug release performance. J. Pharm. Sci., 100(11): 4664-4673.

Ruiz-Rubio L., Alonso M.L., Pérez-Álvarez L., Alonso R.M., Vilas J.L., Khutoryanskiy V.V. (2018). Formulation of Carbopol ${ }^{\circledR} / \mathrm{Poly}(2$-ethyl-2-oxazoline)s mucoadhesive tablets for buccal delivery of hydrocortisone. Polymers, 10(2), 175.

Satoh K., Takayama K., Machida Y., Suzuki Y., Nakagaki M., Nagai T. (1989). Factors affecting the bioadhesive properties property of tablets consisting of hydroxypropyl cellulose and carboxyvinyl polymer. Chem. Pharm. Bull. 37, 1366-1368.

Su C., Ma S.-M., Liu G.-X., Yang S.-G. (2018). Dewetting behaviour of hydrogen bonded polymer complex film under hydrothermal condition. Chinese J. Polym. Sci. 36, 1036-1042. 
658 Su C., Sun J., Zhang X., Shen D., Yang S. (2017). Hydrogen-bonded polymer complex thin 659 film of poly(2-oxazoline) and poly(acrylic acid). Polymers, 9, 363.

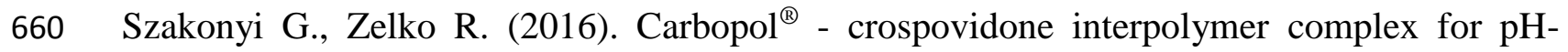
661 dependent desloratadine release. J. Pharm. Biomed. Anal. 123, 141-146.

662 Takayama K., Nagai T. (1987). Application of interpolymer complexation of 663 polyvinylpyrrolidone/carboxyvinyl polymer to control of drug release Chem. Pharm. Bull., 664 35(12), 4921-4927.

Takayama K., Hirata M., Machida Y., Masada T., Sannan T., Nagai T. (1990). Effect of 666 interpolymer complex formation on bioadhesive property and drug release phenomenon of 667 668 compressed tablet consisting of chitosan and sodium hyaluronate. Chem. Pharm. Bull. 38, 1993-1997.

Tan Y.T., Peh K.K., Al-Hanba O. (2001). Investigation of interpolymer complexation between Carbopol and various grades of polyvinylpyrrolidone and effects on adhesion strength and swelling properties. J. Pharm. Pharm. Sci. 4, 7-14.

672

Viegas T.X., Bentley M.D., Harris J.M., Fang Z., Yoon K., Dizman B., Weimer R., Mero A., Pasut G., Veronese F.M. (2011). Polyoxazoline: Chemistry, Properties, and Applications in Drug Delivery. Bioconj. Chem., 22, 976-986.

Yusif R.M., Abu Hashim I.I., Mohamed E.A., El Rakhawy M.M. (2016). Investigation and evaluation of an in situ interpolymer complex of Carbopol with polyvinylpyrrolidone as a matrix for gastroretentive tablets of ranitidine hydrochloride. Chem. Pharm. Bull. 64, 42-51. Zhang F., Lubach J., Watson N.A. Momin S. (2016a). Interpolymer complexation between Polyox and Carbopol on drug release from matrix tablets. J. Pharm. Sci. 105, 2386-2396.

Zhang F., Meng F., Lubach J., Koleng J., Watson N.A. (2016b). Properties and mechanisms of 681 drug release from matrix tablets containing poly(ethylene oxide) and poly(acrylic acid) as release retardants. Eur. J. Pharm. Biopharm. 105, 97-105. formation of nanoparticles and multi-layered coatings based on hydrogen-bonded interpolymer complexes of poly(acrylic acid) with homo- and copolymers of $\mathrm{N}$-vinyl pyrrolidone. Langmuir, 24, 13742-13747. 
689

690

691

692

693

694

695

696

697

698

699

700

701

702

703

704

705

706

707

708

709

710

711

712

713

714

715

716

\section{List of Tables and Figures}

Table 1. Results of elemental, spectroscopic and thermal analysis of samples after swelling in the media mimicking gastro-intestinal tract conditions.

Figure 1. Turbidity of solution mixtures of Carbopol ${ }^{\circledR} 971$ and POZ at different unit-molar ratios. Concentrations of Carbopol ${ }^{\circledR} 971$ and POZ are 0.002 unit-mol/L.

Figure 2. Proposed scheme of complexation between Carbopol ${ }^{\circledR} 971$ and POZ via hydrogen bonding.

Figure 3. Turbidity of 1:1 unit-mol solution mixtures of Carbopol ${ }^{\circledR} 971$ and $\mathrm{POZ}$ as a function of $\mathrm{pH}$. Concentrations of Carbopol ${ }^{\circledR} 971$ and POZ are 0.01 unit-mol/L.

Figure 4. TEM images of IPCs prepared by mixing 0.01 unit-base mol/L solutions of Carbopol ${ }^{\circledR} 971$ and POZ (500 kDa) in 1:1 unit-base molar ratio and adjusting pH by addition of $\mathrm{HCl}(\mathrm{a})$; Proposed mechanism of IPC formation at different $\mathrm{pHs}(\mathrm{b})$.

Figure 5. FTIR spectra of IPC (C971:POZ $50 \mathrm{kDa})$, physical mixture (C971:POZ $50 \mathrm{kDa})$, and individual C971 and POZ $50 \mathrm{kDa}$.

Figure 6. DSC thermograms of: (a) IPC (C971:POZ $50 \mathrm{kDa}$ ); physical mixture (C971:POZ 50 kDa); C971; POZ 50 kDa, (b) IPC (C971:POZ 500 kDa); physical mixture (C971:POZ 500 $\mathrm{kDa}$; C971; and POZ $500 \mathrm{kDa}$.

Figure 7. Comparison of swelling profiles of different matrices in the media mimicking gastrointestinal tract conditions.

Figure 8. Changes in the external appearance of different matrices during swelling test (a): images and resulting matrix diameters generated through the image analysis (b).

Figure 9. Schematic representation of the physicochemical analysis of samples after swelling in the media mimicking gastro-intestinal tract conditions.

Figure 10. FTIR spectra of IPC based on POZ $50 \mathrm{kDa}$ and C 971 after swelling in the media mimicking gastro-intestinal tract conditions.

Figure 11. Release profiles of mesalazine from matrix systems under the conditions mimicking the gastro-intestinal tract. 


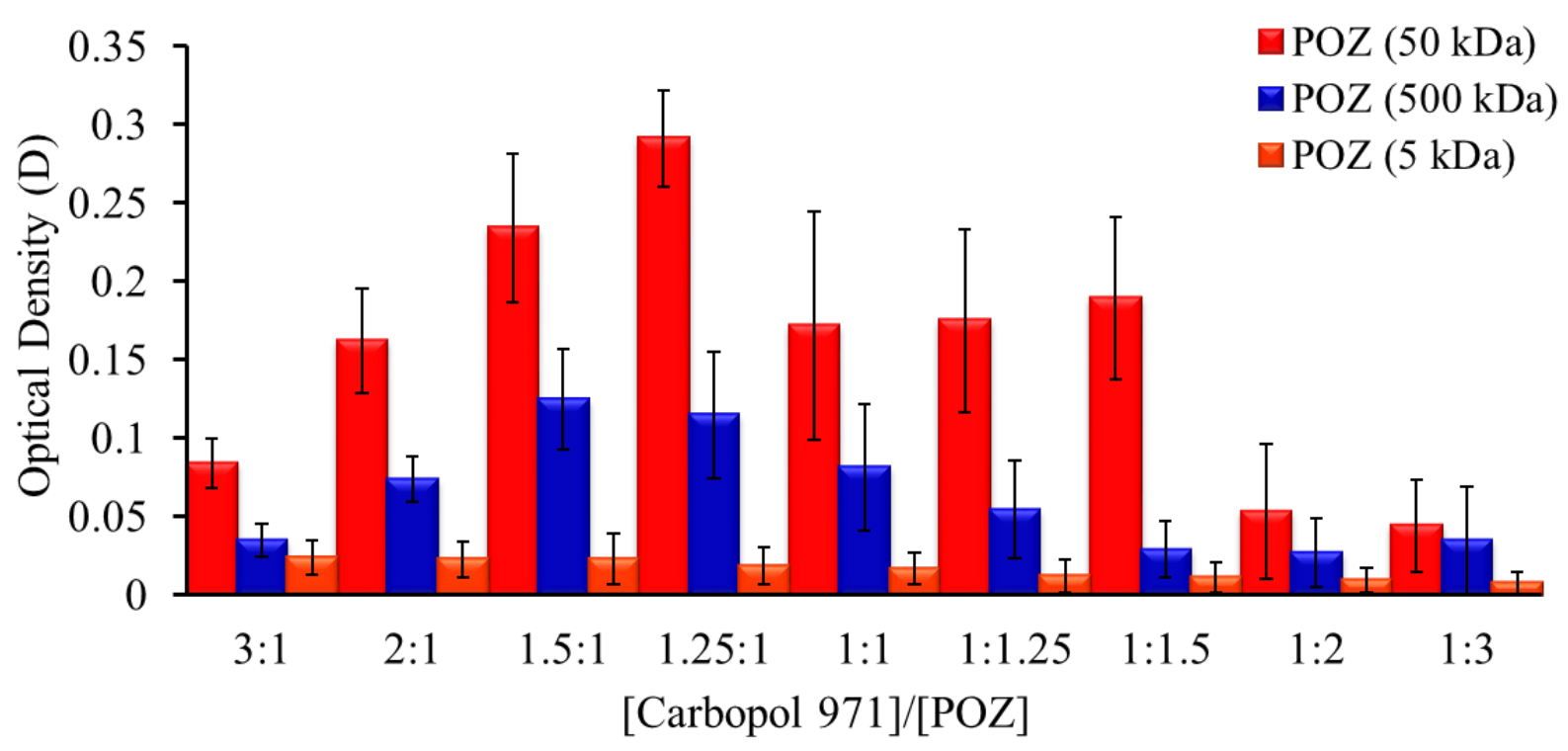

719

720 Figure 1. Turbidity of solution mixtures of Carbopol ${ }^{\circledR} 971$ and POZ at different unit-molar 721 ratios. Concentrations of $\mathrm{Carbopol}^{\circledR} 971$ and $\mathrm{POZ}$ are 0.002 unit-mol/L.<smiles>CC(C)(C)CC(C(=O)O)C(C)(C)C</smiles>

Carbopol 971

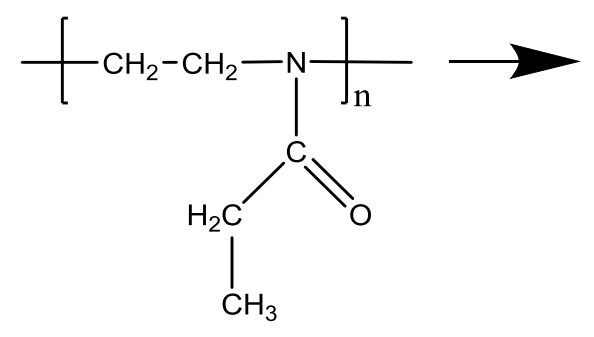

$\mathrm{POZ}$

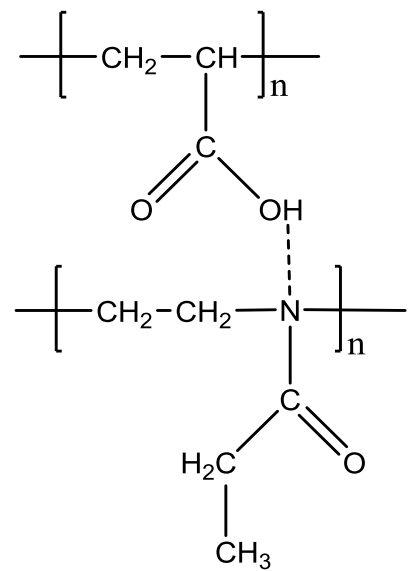

IPC

724 Figure 2. Proposed scheme of complexation between Carbopol ${ }^{\circledR} 971$ and POZ via hydrogen 725 bonding. 


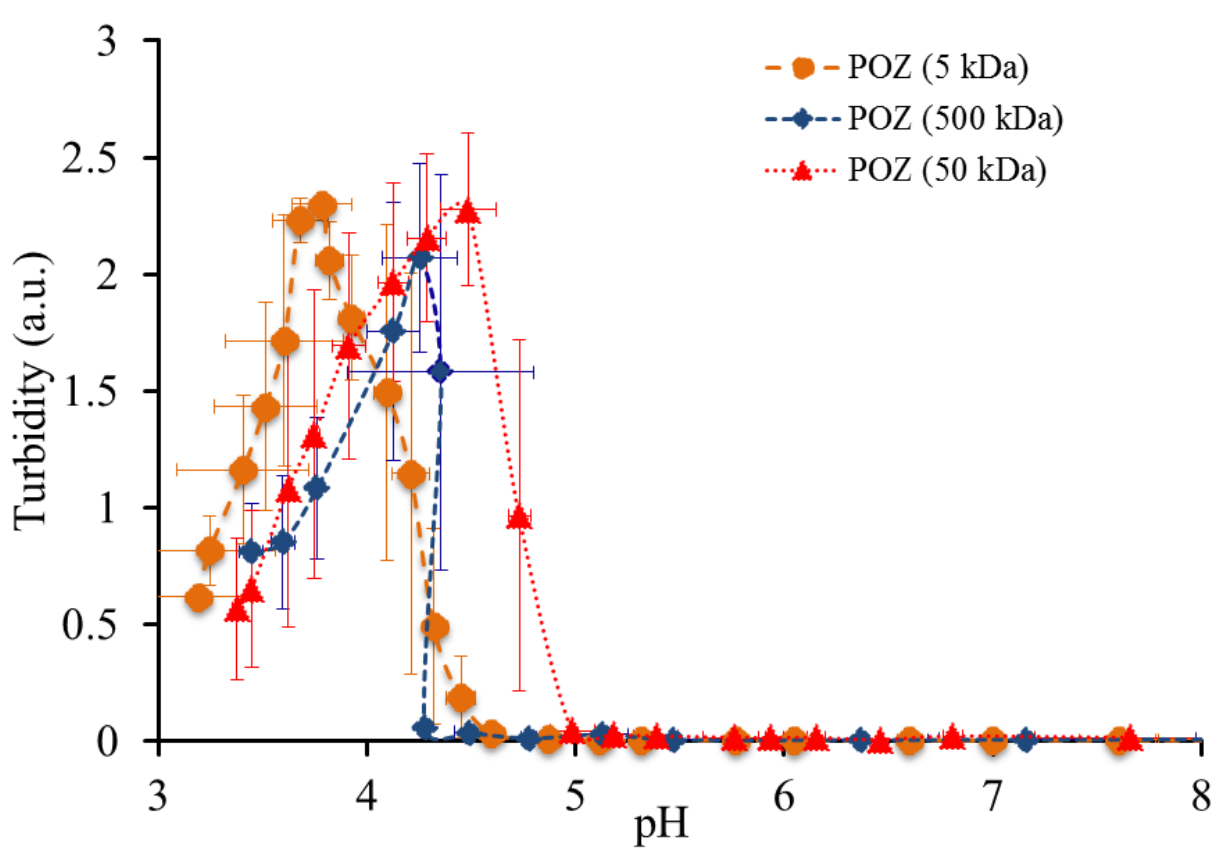

Figure 3. Turbidity of 1:1 unit-mol solution mixtures of Carbopol ${ }^{\circledR} 971$ and POZ as a function of $\mathrm{pH}$. Concentrations of $\mathrm{Carbopol}^{\circledR} 971$ and POZ are 0.01 unit-mol/L.

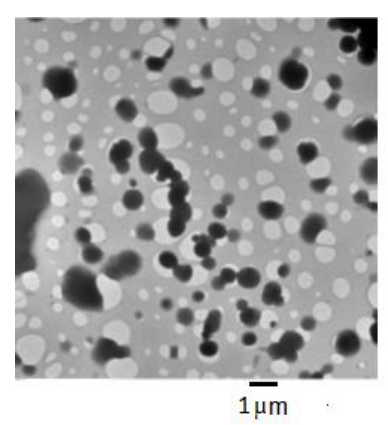

$\mathrm{pH}=2.14$

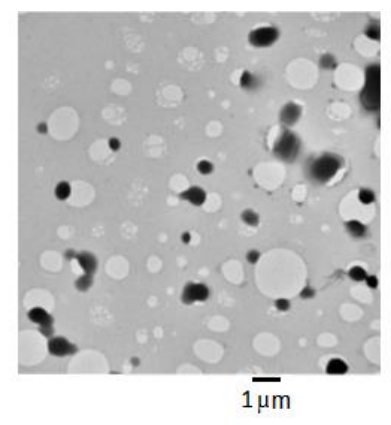

$\mathrm{pH}=2.50$

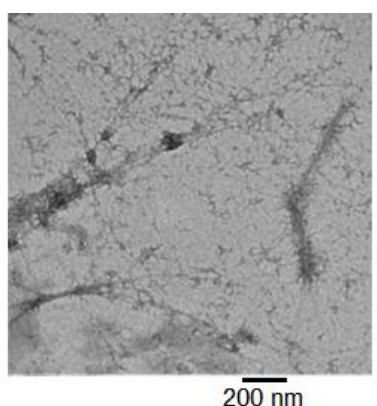

$\mathrm{pH}=4.54$

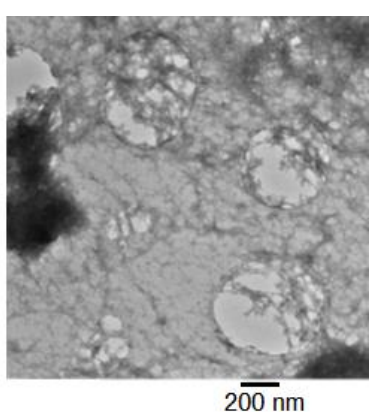

$\mathrm{pH}=4.79$

732

(a)

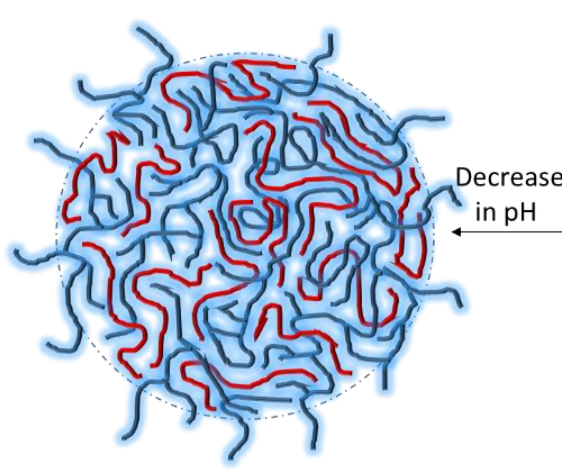

Spherical IPC aggregates

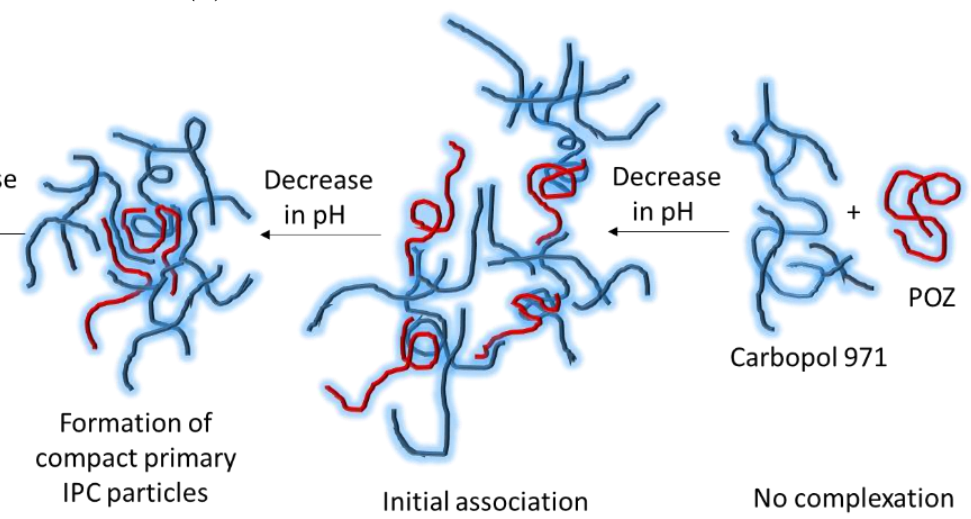

(b) 
735 Figure 4. TEM images of IPCs prepared by mixing 0.01 unit-base mol/L solutions of 736 Carbopol $^{\circledR} 971$ and POZ $(500 \mathrm{kDa})$ in 1:1 unit-base molar ratio and adjusting pH by addition 737 of $\mathrm{HCl}$ (a); Proposed mechanism of IPC formation at different $\mathrm{pHs}(\mathrm{b})$.

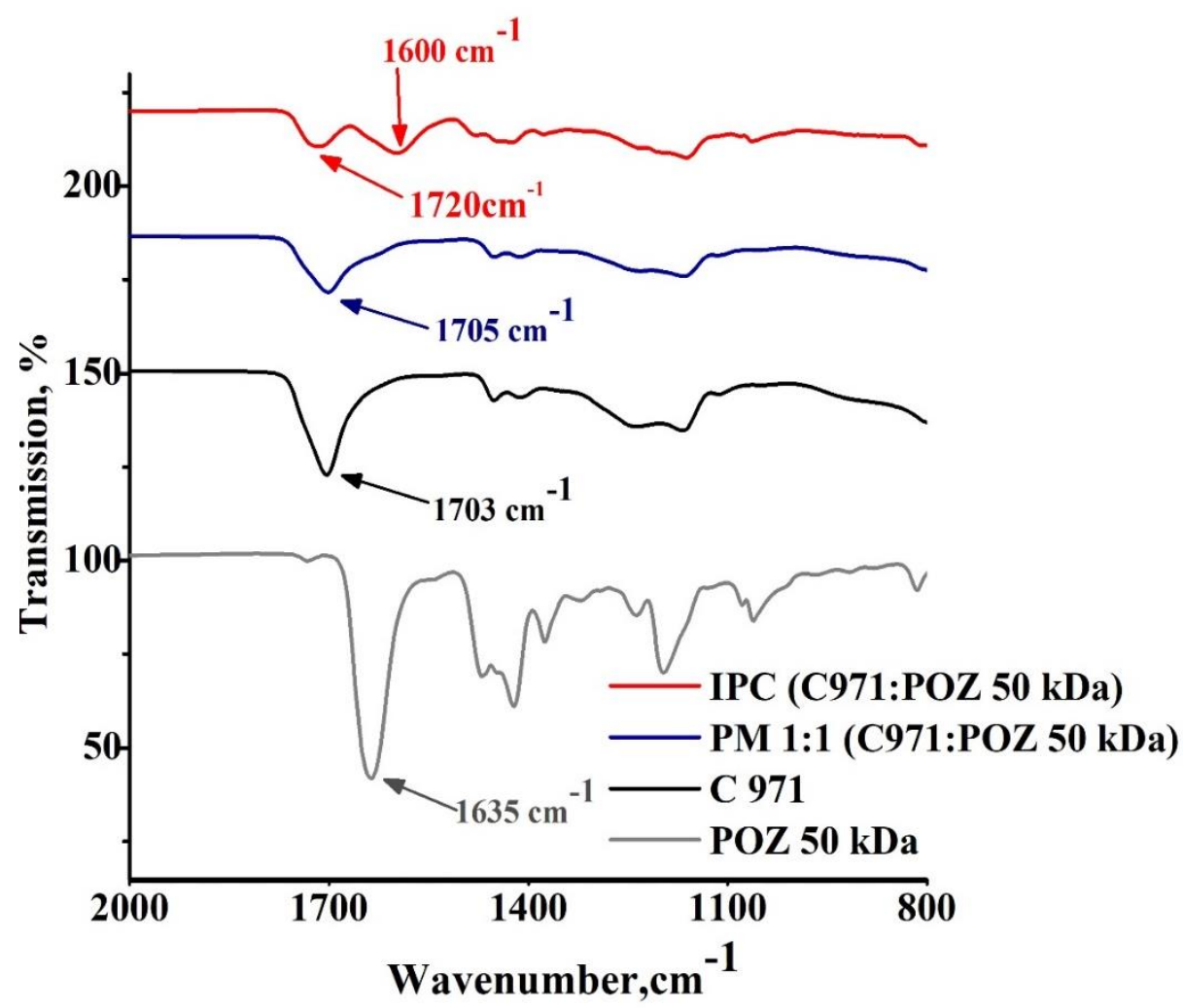

739

740 Figure 5. FTIR spectra of IPC (C971:POZ $50 \mathrm{kDa}$ ), physical mixture (C971:POZ $50 \mathrm{kDa})$, 741 and individual C971 and POZ $50 \mathrm{kDa}$. 


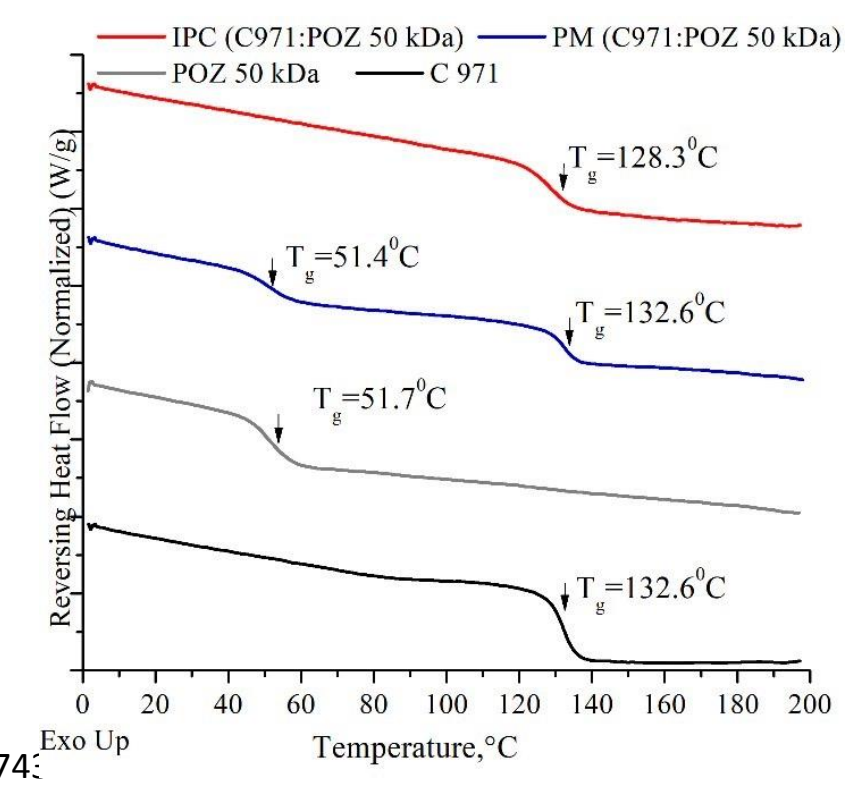

(a)

745

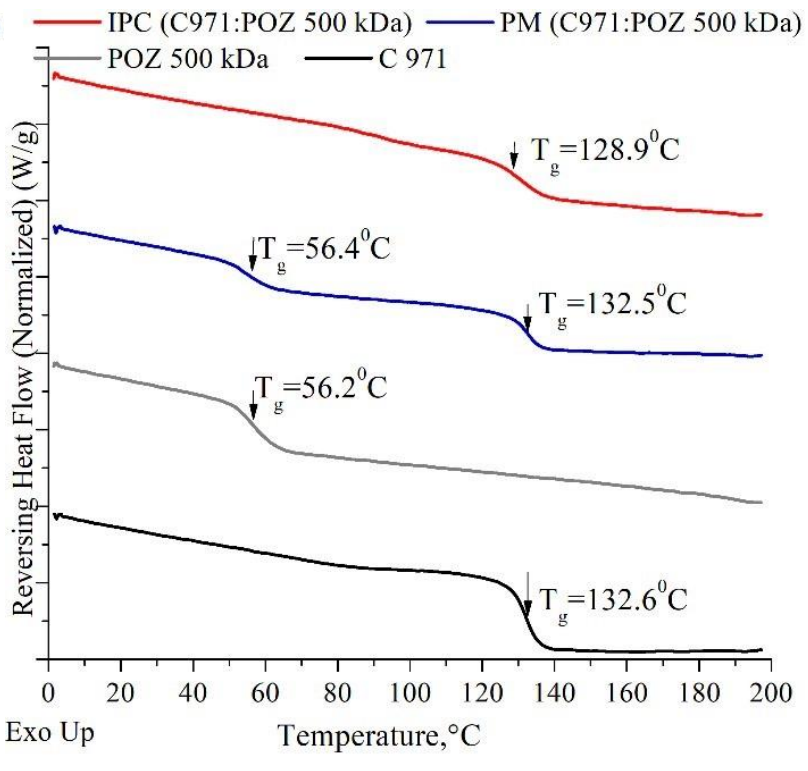

(b)

Figure 6. DSC thermograms of: (a) IPC (C971:POZ $50 \mathrm{kDa})$; physical mixture (C971:POZ 50 kDa); C971; POZ 50 kDa, (b) IPC (C971:POZ 500 kDa); physical mixture (C971:POZ 500 kDa); C971; POZ 500 kDa.

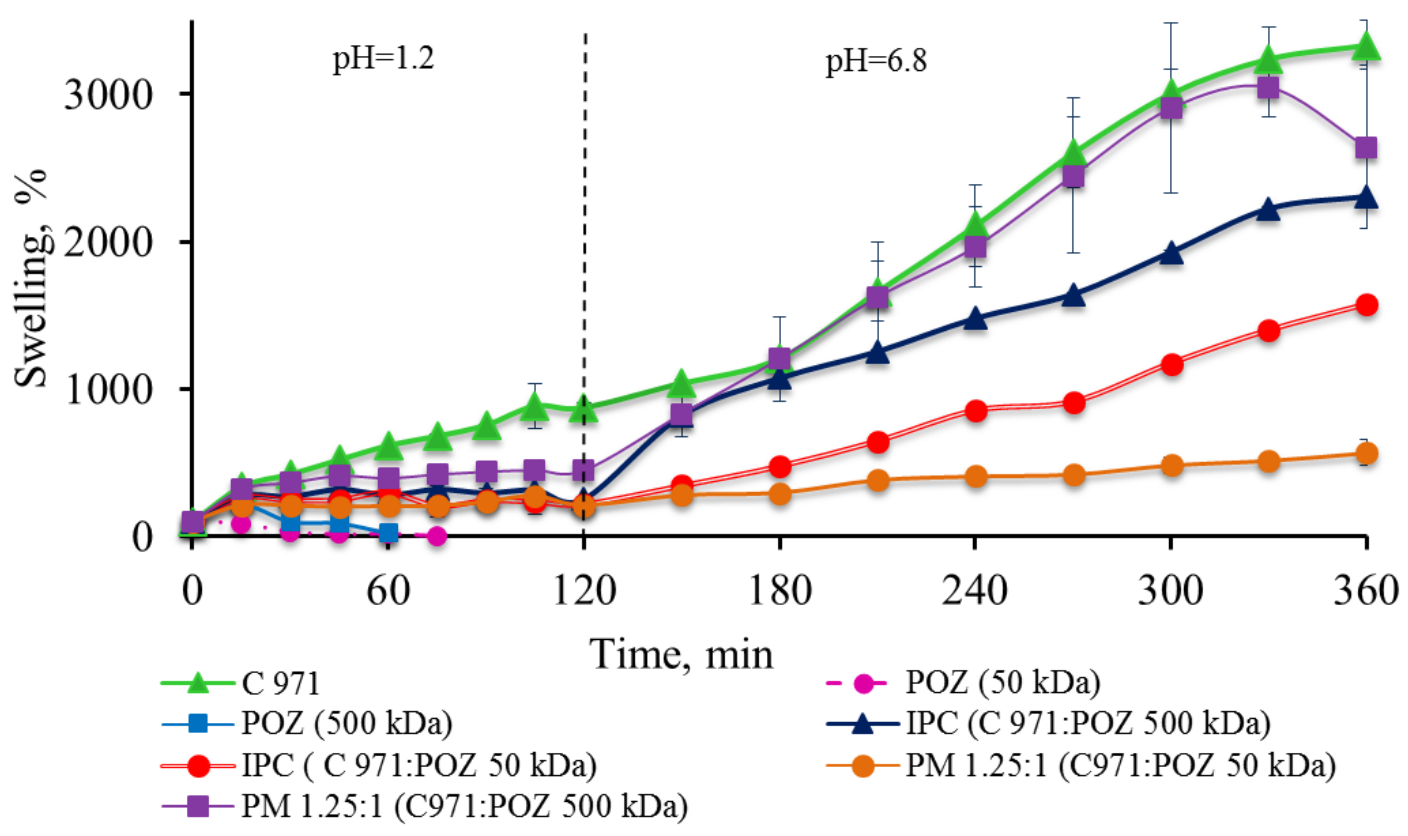


754 Figure 7. Comparison of swelling profiles of different matrices in the media mimicking gastrointestinal tract conditions.

756

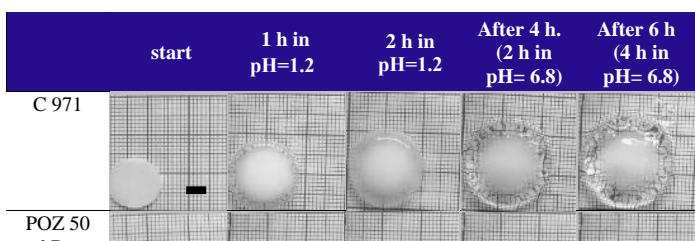

$\mathrm{kDa}$

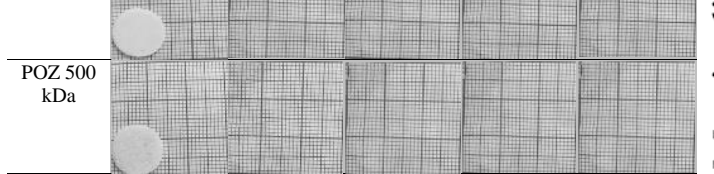

$\mathrm{PM}$
$1.25: 1$

$1.25: 1$
$(\mathrm{C} 971: \mathrm{POZ}$

$50 \mathrm{kDa})$

PM
$1.25: 1$
$(C 971: \mathrm{POZ}$

(C971:POZ
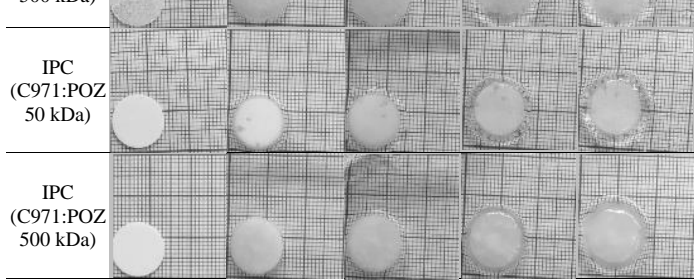

(a)

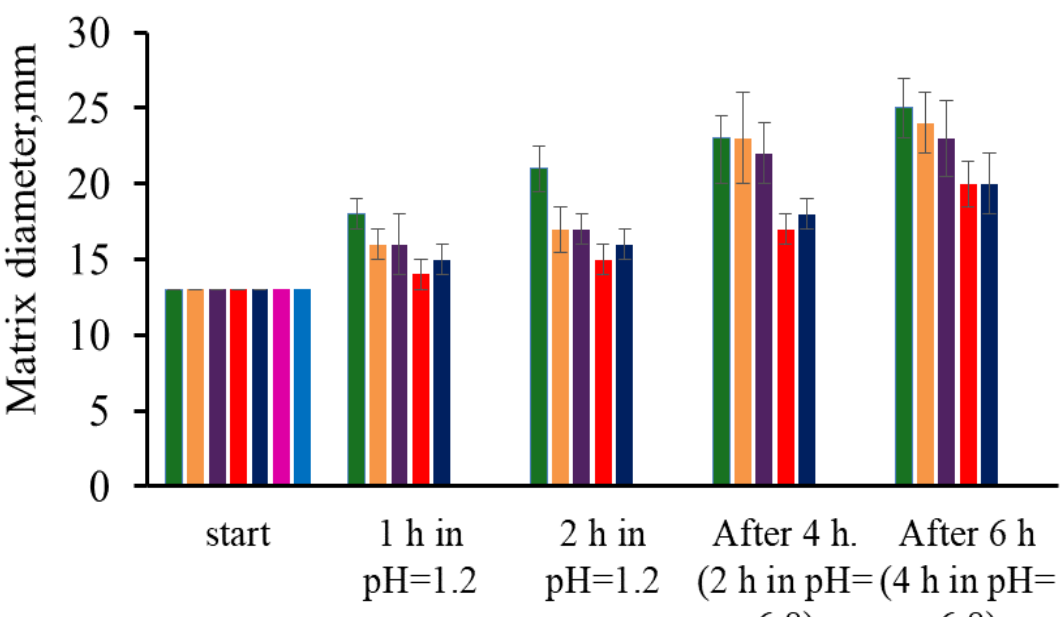

- $\mathrm{C} 971$

- PM 1.25:1 (C971:POZ $500 \mathrm{kDa})$ - IPC (C971:POZ $500 \mathrm{kDa})$ - POZ $500 \mathrm{kDa}$
— PM 1.25:1 (C971:POZ 50 kDa) IPC (C971:POZ $50 \mathrm{kDa})$ - POZ $50 \mathrm{kDa}$

(b)

759 Figure 8. Changes in the external appearance of different matrices during swelling test (a): images and resulting matrix diameters generated through the image analysis (b). Scale bar is 5 $\mathrm{mm}$ 


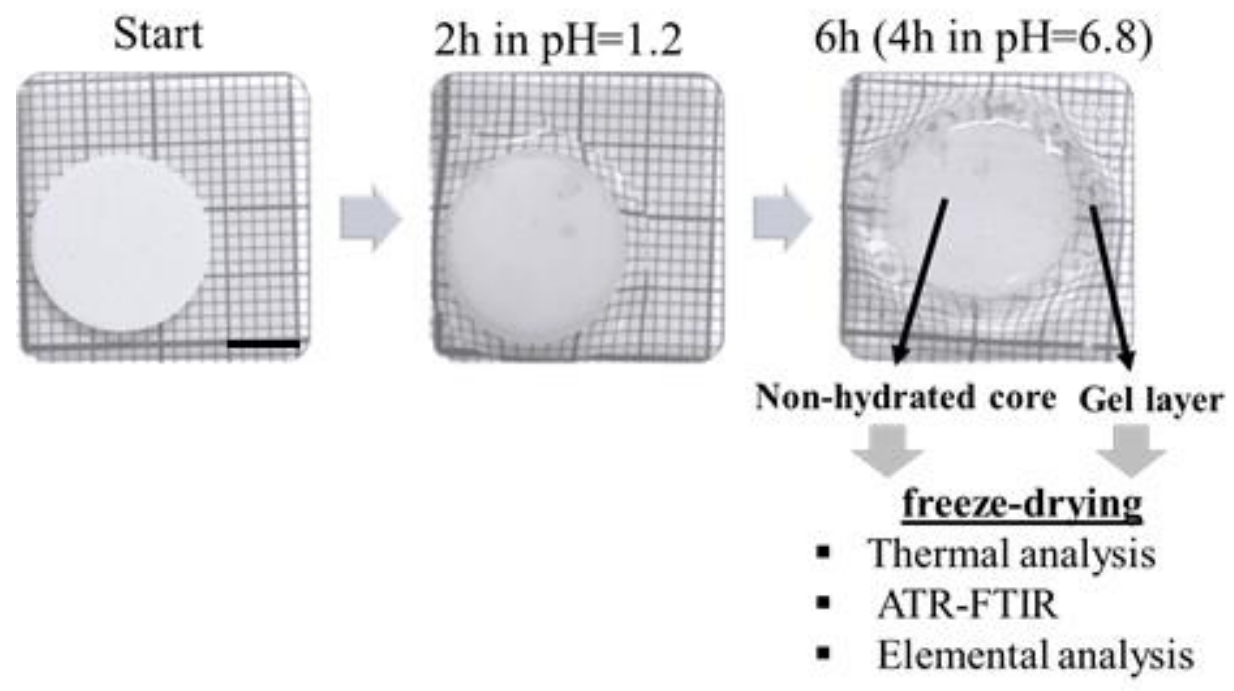

765 Figure 9. Schematic representation of the physicochemical analysis of samples after swelling in the media mimicking gastro-intestinal tract conditions. Scale bar is $5 \mathrm{~mm}$

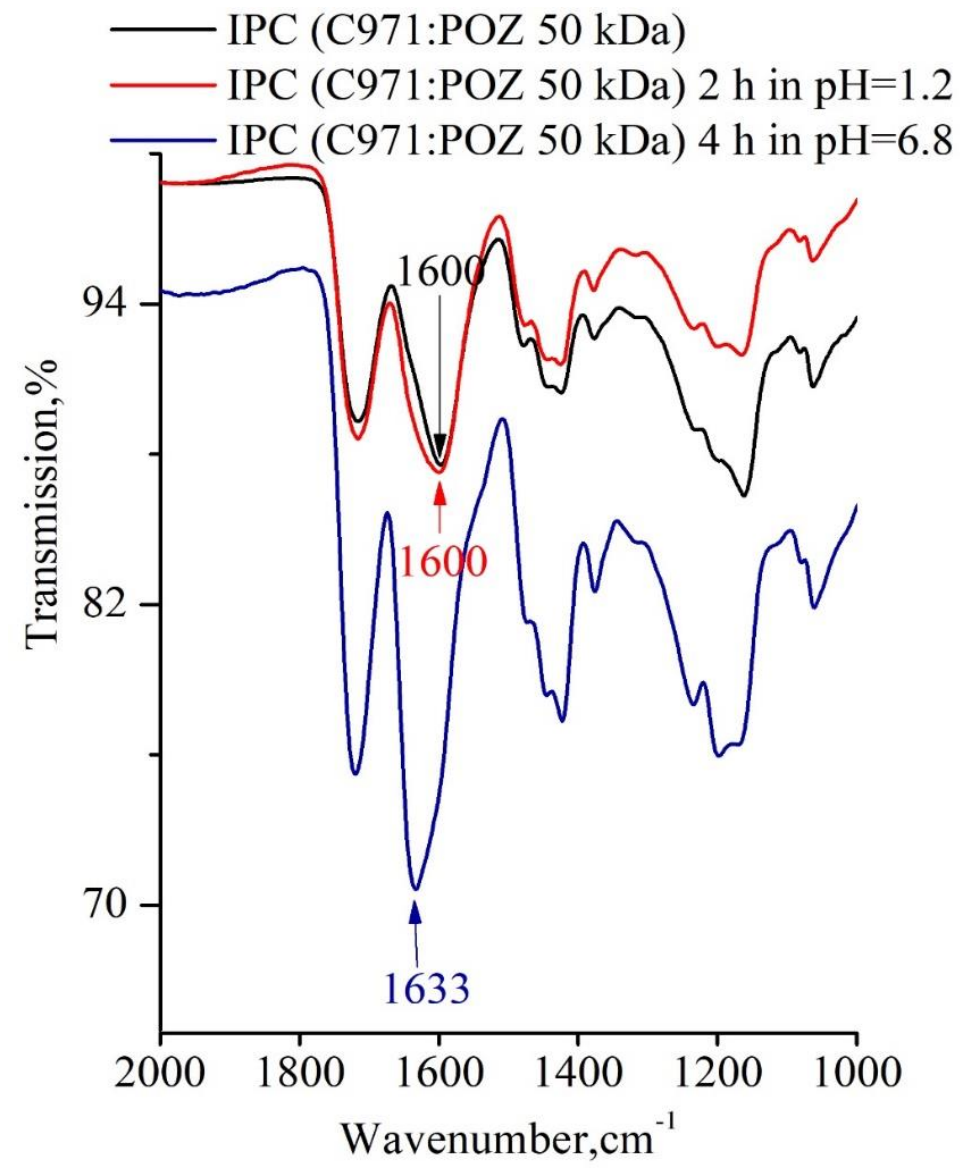

769 Figure 10. FTIR spectra of IPC based on POZ $50 \mathrm{kDa}$ and C 971 after swelling in the media mimicking gastro-intestinal tract conditions. 


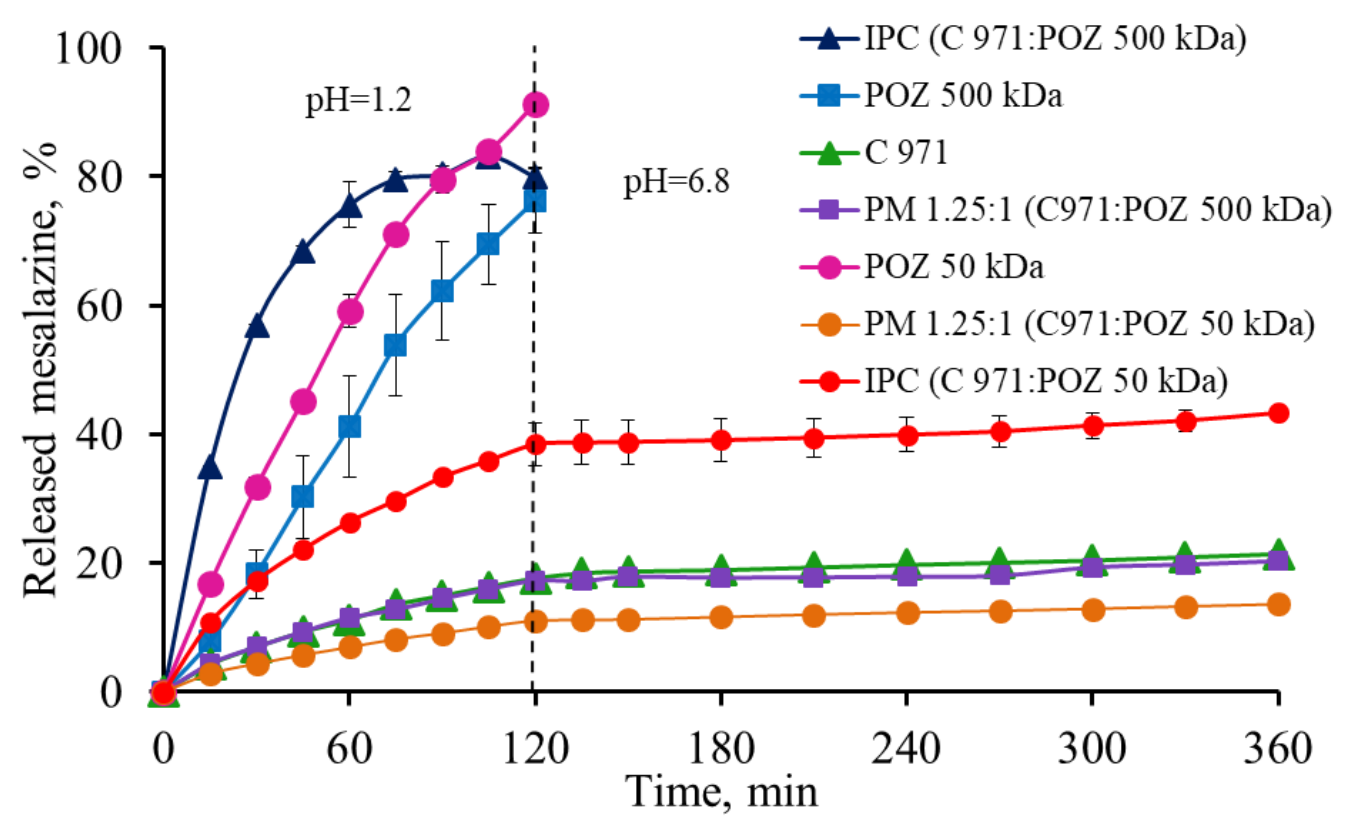

774 Figure 11. Release profiles of mesalazine from matrix systems under the conditions mimicking 775 the gastro-intestinal tract. 